\title{
Graphene and Its Composites with Nanoparticles for Electrochemical Energy Applications
}

\author{
Qing $\mathrm{Li}^{\mathrm{a}, \dagger}$, Nasir Mahmood ${ }^{\mathrm{b}, \dagger}$, Jinghan $\mathrm{Zhu}^{\mathrm{b}}$, Yanglong $\mathrm{Hou}^{\mathrm{b}, *}$, and Shouheng Sun ${ }^{\mathrm{a}, *}$ \\ aDepartment of Chemistry, Brown University, Providence, Rhode Island 02912, USA \\ E-mail: ssun@brown.edu \\ ${ }^{b}$ Department of Materials Science and Engineering, College of Engineering, Peking University, \\ Beijing 100871, China \\ E-mail: hou@pku.edu.cn
}

\section{Summary}

Graphene is a two dimensional (2D) planar and hexagonal array of carbon atoms and has been studied extensively as advanced nanomaterials for important technological applications. This review summarizes the recent developments in chemistry, materials and energy applications of graphene, doped graphene and their composites with nanoparticles (NPs). It first highlights the new chemistry used to synthesize high quality graphene. It then outlines the methodologies developed to dope graphene with heteroatoms to modify and control graphene properties. It further describes the general approaches to graphene-NP composites via either direct NP growth onto graphene or self-assembly of the pre-formed NPs on graphene surface. These graphene-NP composites provide some ideal systems for studying synergistic effects between graphene and NPs on catalysis. The review focuses on applications of graphene-NP composites in increasing electrochemical energy storage density and in catalyzing chemical reactions with much desired electrochemical efficiencies.

\footnotetext{
$\dagger$ These two authors contributed equally to this review article.
} 
Keywords: graphene, doped-graphene, liquid phase exfoliation, graphene-nanoparticle composites, energy storage, energy conversion.

\section{Introduction}

Graphene is a two dimensional (2D) planar and hexagonal array of carbon atoms. Each of these carbons is $s p^{2}$-hybridized and is linked together by three strong C-C $\sigma$ bonds of $120^{\circ}$ apart. The unhybridized $p$-orbital is perpendicular to the $s p^{2}$-hybridization plane, conjugating with the same $p$-orbitals on other carbon atoms via $\pi$ interaction across the entire 2D plane surface [1].

With $\sigma$ bond of $1.46 \AA$ and lattice parameter of $2.46 \AA$ [2], graphene possesses very unique electronic and mechanical properties [3]: its valence band mirrors its conduction one with two bands intersecting at its Fermi level $[4,5]$, giving graphene the unique zero-gap semiconductor properties with charge carrier mobility $>2 \times 10^{5} \mathrm{~cm}^{2} / \mathrm{Vs}$ at an electron density of $2 \times 10^{11} \mathrm{~cm}^{-2}$ [68] and thermal conductivity > $3000 \mathrm{~W} / \mathrm{mK}$ [9]; the strong $\sigma-\pi$ bonds make graphene mechanically robust with its young's modulus $>0.5-1 \mathrm{TPa}[10]$. The complete planar exposure of the carbon atoms renders graphene a theoretical surface area $>2500 \mathrm{~m}^{2} / \mathrm{g}[11,12]$. The delocalized $\pi$ electrons are also responsible for various interactions between any two graphene layers and between graphene and a substrate [4]. Thus, graphene has been coupled with metals $[13,14]$, alloys [15], oxides [16, 17], and other polymeric compounds to form composites [1822]. The properties of graphene can be further modified by the introduction of heteroatoms in the graphitic plane [23]. The replacement of a carbon atom with another atom breaks the electroneutrality of the $\sigma-\pi$ network within graphene, making the $2 \mathrm{D}$ network more susceptible to chemical reactions [24]. The new properties evolved from graphene and its hybrid structures 
have been explored extensively for advanced technological applications in electronics, optics, catalysis and energy storage/conversion [2, 25-33].

This review intends to summarize the recent developments in chemistry, materials and energy applications of graphene, doped graphene and their composites with nanoparticles (NPs). It includes both the work from the author's groups and the representative examples from others to highlight the important aspects on graphene chemistry and applications. It will first summarize new chemistry used to synthesize high quality graphene. It will also outline the methodologies developed to dope graphene with heteroatoms to modify and control graphene properties. The more controlled synthesis leading to high quality graphene and its solutions in various solvents allows for rational assembly of NPs on graphene surface, providing an ideal system to study synergistic effect between graphene and NPs on the enhanced catalytic properties. The review will focus on applications of graphene-based nanomaterials in electrochemical energy storage (lithium based batteries and supercapacitors) and conversion devices (fuel cells and electrolyzers).

\section{Synthesis of Graphene via Liquid Phase Exfoliation}

Synthesis of high quality graphene is key to understanding and controlling its physical and chemical properties [34, 35]. Figure 1 summarizes the methods (as well as the costs associated with the methods) used to prepare graphene. Graphite is the natural choice as a starting precursor to produce graphene as the graphitic layers are already present within the graphite structure and graphene can be obtained by simply "peeling off" these graphitic layers via mechanical and/or chemical means [36-39]. Alternatively, graphene can be prepared by chemical vapor deposition 
(CVD) [33, 40-46], which requires high vacuum (to avoid contaminants from environment) and high temperature (to facilitate precursor decomposition).

The liquid phase exfoliation (LPE) is a process in which graphite is exposed to liquid medium and single layer of graphitic plane is peeled off [34]. In graphite, graphitic planes are held together by interlayer attractions with the interaction area energy density at $\sim 40 \mathrm{~mJ} / \mathrm{m}^{2}$ (Figure 2a) [35, 47]. The potential energy associated with these interactions is inversely proportional to the distance between the adjacent layers. Therefore, mechanical, thermal, and/or chemical means are often applied to counter these attractions in the exfoliation process and proper molecules (either as a solvent or as a surfactant) can be explored to stabilize graphene against its re-stacking [37, 48]. Alternatively, exfoliation can be achieved electrochemically in solution via injecting negative charge to the graphitic layers for layer separation $[47,49,50]$. Recent experiments have demonstrated that LPE is a much easier process to produce the stabilized graphene than any of the other strategies demonstrated $[37,48]$.

To overcome the interfacial forces of pristine graphite, a proper organic solvent with "strong" binding power to the graphitic plane needs to be selected to counter the interfacial interaction among the graphite layers and to stabilize the graphene once the single sheet is peeled off (Figure 2a) [35]. N-methylpyrrolidone (NMP), N,N-dimethyl formamide (DMF), orthodichlorobenzene (o-DCB) are the common solvents used for graphene formation and stabilization [37, 51]. Ionic liquid, such as 1-hexyl-3-methyl-imidazolium hexafluorophosphate (HMIH), is also used to exfoliate graphite with graphene concentration reaching up to 5.33 $\mathrm{mg} / \mathrm{mL}$ [52]. Recently, graphene is synthesized in $10-12 \mathrm{wt} \%$ in acetonitrile, $\mathrm{CH}_{3} \mathrm{CN}$, by first pre-heating the graphite precursor to cause graphite layers to expand and by reacting the expanded layers with $\mathrm{CH}_{3} \mathrm{CN}$ in the common solvothermal and sonication condition (Figure 3) 
[53]. When the graphite swells, the small $\mathrm{CH}_{3} \mathrm{CN}$ can be inserted into the graphitic interlayers, facilitating graphene separation and stabilization. Similarly, 1,2-dichloroethane (DCE) is used as a solvent to insert into the expanded graphitic layers for graphene formation, in which case poly (m-phenylenevinylene-co-2,5-dioctoxy-p-phenylenevinylene) (PmPV) is used to stabilize the graphitic sheets against their re-stacking [54]. To make graphene in a greener environment, water has been pursued as the solvent for graphite exfoliation. But as graphite/graphene is hydrophobic, proper surfactant has to be added so that the exfoliated graphene can be coated with the surfactant and become water dispersible [37]. In this approach, pyrene derivatives, such as 1-aminopyrene and sodium 1-pyrenesulfonate, are the popular choice due to the strong pyrene-graphitic $\pi-\pi$ interaction and the graphene concentration can reach as high as $1 \mathrm{mg} / \mathrm{mL}$ [48, 55]. Alternatively, 7,7,8,8-tetracyanoquinodimethane (TCNQ)-anion can be used to peel off graphitic layers and to stabilize graphene. Graphene product obtained from the TCNQ solution contains 2-3 graphitic layers that are dispersible in water with the concentration reaching up to $20 \mu \mathrm{g} / \mathrm{mL}[56]$.

In addition to the use of solvent/surfactant, sonication is also applied as a physical mean in the exfoliation process to "shake off" the graphic layers. For example, in the synthesis of graphene from graphite in NMP, simply applying a $23 \mathrm{~W}$ sonication from 0.5 to $460 \mathrm{~h}$ helps to increase the concentration of graphene dispersion in NMP from 0.05 to $>1 \mathrm{mg} / \mathrm{mL}$ (Figure $2 \mathbf{b}$ ) [57]. If the graphene dispersion has a broad size distribution, then centrifugation can be applied to separate graphene flakes by size, further purifying the graphene product (Figure 2c) [58].

To reduce graphitic plane interaction for easy exfoliation, graphite is often oxidized to have O-doping. The O-doping can weaken the $\pi-\pi$ interaction between any two graphitic planes, leading to the easy formation of single layer of graphitic sheets [59]. Unlike graphene, which is 
hydrophobic, the graphene oxide (GO) sheet is hydrophilic and is readily dispersed in a polar solvent. One obvious drawback of this O-doping is that it lowers the conductivity and mechanical strength of the graphitic product observed from the pristine graphene. As a result, the as-synthesized GO must be reduced to remove $\mathrm{O}$ from the graphitic plane with minimized surface defects. A variety of reducing agents, including borohydrides, hydrazine, metal hydrides, and hydrogen halides, have been employed to reduce GO to graphene [60]. Depending the reducing power the agent displays, GO may only be reduced partially but with their conductivity recovered close to the level observed from the pristine graphene. Such partially reduced GO are often referred to as reduced graphene oxide (rGO), and are used widely in catalytic studies due to their good conductivity, solubility and binding capability.

\section{Doped Graphene}

Chemical modification of graphene with other elements has been explored extensively to improve intrinsic properties, especially catalytic properties, of graphene derivatives. It is observed that doping heteroatoms (e.g., N, B, P, or S) into the graphene lattice can tune the electronic and geometric features of the resultant graphene by providing more active sites for stronger molecular adsorption [61-63]. Such doping is important to further tune graphene properties for electrocatalytic reactions.

\subsection{Nitrogen (N)-Doped Graphene}

$\mathrm{N}$ has a comparable atomic size with $\mathrm{C}$, and has five valence electrons. It can form a strong covalent C-N bond. Once the bond is formed, the electronegative $\mathrm{N}$ (electronegativity: 3.04) can break the charge neutrality on $\mathrm{C}$ (electron negativity: 2.55) in the $s p^{2}$ carbon lattice. Depending on where $\mathrm{N}$ binds to $\mathrm{C}, \mathrm{N}$ is often categorized as graphitic $\mathrm{N}$, pyridinic $\mathrm{N}$ and pyrollic $\mathrm{N}$. As $\mathrm{N}$ 
can be viewed as an $n$-type $\mathrm{C}$ dopant, these different $\mathrm{N}$-dopings render the otherwise ordered carbon honeycomb planar structure disordered and donate more electrons to the graphene network to shift the neutralized charge distribution on the un-doped graphene lattice [64]. Nbinding modes as illustrated in Figure 4a can be characterized by $\mathrm{N}$ 1s binding energies by $\mathrm{X}$ ray photoelectron spectroscopy (XPS). Pyridinic $\mathrm{N}(398.6 \pm 0.3 \mathrm{eV})$ is formed when $\mathrm{N}$ binds to $\mathrm{C}$ at the edge of the graphene layer, contributing one more $p_{\pi}$ electron to the graphitic $\pi$ system. Graphitic N $(401.3 \pm 0.3 \mathrm{eV})$ is the result of in-plane doping and contributes two $p_{\pi}$ electrons. The pyrrolic $\mathrm{N}(400.5 \pm 0.3 \mathrm{eV})$ is assigned to nitrogen atoms in a pentagon structure $[65,66]$. The oxidized $\mathrm{N}$, such as a pyridinic- $\mathrm{N}^{+}-\mathrm{O}^{-}$has an even high binding energy (402-405 eV) [65]. Noteworthy, graphitic and pyridinic N's are dominant dopants in the N-graphene catalysts and have some obvious enhancing effects on electrocatalytic reactions, including ORR [61, 62, 67], water oxidation [68], selective $\mathrm{CO}_{2}$ reduction [69], etc. Figures $\mathbf{4 b}$ and $\mathbf{4 c}$ show the atomic charge and spin density distribution on the $\mathrm{N}$-graphene $\left(\mathrm{C}_{45} \mathrm{NH}_{20}\right)$ with a single pyridinic $\mathrm{N}$, as calculated by the density functional theory (DFT) [70]. The atomic charge and spin density distribute non-uniformly around N. Specifically, the carbon atom C6, the second neighbor of the nitrogen, has the largest atomic charge value (0.169) while the carbon atom C37 in the opposite position of the same hexagon ring as the nitrogen has the largest spin density (0.235). The active sites for ORR on single $\mathrm{N}$-graphene are further identified as carbon atoms possessing either high positive spin density or high positive atomic charge density, and the ORR occurs in a direct fourelectron pathway on $\mathrm{N}$-graphene. In a structure containing graphitic $\mathrm{N}$, the $\mathrm{C}-\mathrm{N}$ bond is much shorter (comparable to an $\mathrm{O}-\mathrm{O}$ bond) [71], facilitating $\mathrm{O}_{2}$ adsorption and subsequent dissociation of the O-O bond. In contrast, pure graphene without $\mathrm{N}$-doping does not have such catalytic activities. 
$\mathrm{N}$-graphene can be synthesized by chemical vapor deposition (CVD) of a volatile N-precursor $[62,72]$, thermal annealing of graphene under $\mathrm{NH}_{3}[73,74]$, arc discharge between carbon electrodes in the presence of pyridine or ammonia [75], exposing graphene to nitrogen plasma [76, 77], hydrothermal reaction of $\mathrm{GO}$ with $\mathrm{NH}_{4} \mathrm{OH}[78,79]$, and high-temperature pyrolysis of GO with N-containing organic precursors (cyanamide, melamine, etc.) [80-82]. Supercritical reaction can also be applied to make $\mathrm{N}$-graphene, as demonstrated in exfoliation of few-layer graphene sheets in supercritical $\mathrm{CH}_{3} \mathrm{CN}$ at $310^{\circ} \mathrm{C}$, in which $\mathrm{N}$ atoms from $\mathrm{CH}_{3} \mathrm{CN}$ can enter into the graphene lattice and form covalent bonds with carbon atoms [50].

\subsection{Graphene Doped with Other Elements}

Boron (B) is electron-deficient with electron negativity 2.04. When B substitutes C in the $s p^{2}$ lattice, electrons from C-C $\pi^{*}$ anti-bonding orbital is "pulled" to the vacant $2 p_{z}$ orbital of B, which pushes the Fermi level of the graphene to the conducting band [83]. Consequently, a fraction of lone pair electrons appears in B $2 p_{z}$ and these partially filled $2 p_{z}$ orbitals can act as the electron-donating sites [83]. B-doping can be performed by the heat treatment of carbon and boron powder [84], arc charge using graphite electrodes in the presence $\mathrm{H}_{2}$ and $\mathrm{B}_{2} \mathrm{H}_{6}$ or using boron-stuffed graphite electrodes [75], CVD of benzene and triphenylborane (TPB) [83], or the reduction of GO by a borane-tetrahydrofuran adduct solution under reflux [85].

Sulfur (S) is larger than C, but has a very close electron negativity (2.58) to C. Doping S into graphene may not show the obvious break in graphene charge neutrality [86], but can induce the structural strain across the graphitic plane, which may further change the electronic structure of graphene [87]. The strain-induced charge localization and the lone pairs in the $\mathrm{S}$ atoms are more pronounced than nitrogen for its large polarizability [88]. S in the graphitic lattice is often present at the edge sites in thiophene-like structure [89, 90], because it is difficult for an $\mathrm{S}$ to 
substitute a $s p^{2}-\mathrm{C}$ [91]. $\mathrm{S}$ in the doped structure can also be present as thiolate [90] and sulfoxide [92] forms. S-graphene have been prepared via thermal annealing of $\mathrm{GO}$ and $\mathrm{H}_{2} \mathrm{~S}$ or benzyl disulfide (BDS) [89, 91, 93, 94].

Phosphorus (P) is larger but less electronegative (2.19) than C. Theoretical calculations suggest that "P-substitution" in the graphene lattice distorts the $s p^{2}$ lattice and impairs the spin density [95]. P-graphene's are prepared by thermal annealing of GO and P-containing precursors such as 1-butyl-3-methlyimidazolium hexafluorophosphate [96], or by annealing GO and triphenylphosphine at $700-1000^{\circ} \mathrm{C}$ in argon [8]. Both P-C and P-O bonds are identified by XPS [97]. But more studies are needed to demonstrate whether $\mathrm{P}$ can substitute the $s p^{2} \mathrm{C}$ in the graphene lattice [98].

In addition to single element doping described, binary and ternary doping of $\mathrm{N}, \mathrm{B}, \mathrm{S}$, and $\mathrm{P}$ into graphene is also studied to further tune electronic structure and catalysis of the graphene. Generally, B-, or S- or P-graphene is less efficient than N-graphene for ORR, showing a twoelectron reduction pathway [86]. However, graphene co-doped with N and B (or S) become more active and stable for ORR than $\mathrm{N}$-graphene in alkaline solution [91, 99]. DFT calculations have revealed that the catalysis enhancement results from the redistribution of spin and charge densities by the dual doping, creating more active sites on the carbon in the graphitic network. The same concept has been applied to form ternary (N, B, and P) doped graphene to further optimize the ORR catalysis [100]. The B-doping reinforces the $s p^{2}$-structure and increases the portion of pyridinic- $\mathrm{N}$ sites in the carbon lattice, whereas P-doping enhances the charge delocalization of the carbon atoms and produces carbon structures with increased edge sites. However, it should be pointed out that the binary and ternary doping generally result in rather 
complicated surface structures of graphene and the accurate characterization and simulation of these heterogeneous structures are highly desirable.

\section{Nanocomposites of Graphene and NPs}

The large surface area, electrical conductivity, and mechanical strength make graphene the most promising substrate to be coupled with NP catalysts to achieve high catalytic performance for energy applications $[101,102]$. Depending on the Fermi level/work function of graphene and metal NPs, interfacial charge transfer can be controlled from graphene to NPs or from NPs to graphene $[103,104]$. Therefore the graphene-NP junction area can become catalytically "hot" spots to catalyze the otherwise impossible reaction, or to further enhance the NP catalysis.

To enhance interfacial charge transfer, there must exist strong interaction between graphene and NPs [105]. Graphene-NP nanocomposites can be made by growing NPs directly on graphene surface or by simple mixing of graphene and pre-made NPs. To ensure strong NP-graphene interaction, graphene is often pre-functionalized or doped with heteroatoms to provide the necessary anchoring sites for the growth of NPs [106].

\subsection{Direct Growth of NPs on Graphene}

Hydrothermal and/or solvothermal methods have been used widely to growth NPs on GO and/or graphene [1]. This is demonstrated nicely in producing GO-metal oxide/sulfide NP composites. In the process, NPs nucleate and grow on GO in a high-temperature and highpressure environment and the existing hydroxyl and carboxyl functional groups on GO serve as nucleation sites for NP growth through forming covalent metal-O-C bonds [107, 108]. Similarly, by reacting metal precursors, $\mathrm{S}$ (or $\mathrm{N}$ ) sources, and graphene in appropriate conditions (temperature, solvent, surfactant), composites of graphene-metal sulfide, oxide and nitride NPs 
are obtained $[109,110]$. Using similar solvothermal approach, $\mathrm{SnS}_{2} \mathrm{NPs}$ are decorated on rGO in ethylene glycol using $\mathrm{SnCl}_{4} \cdot 5 \mathrm{H}_{2} \mathrm{O}$, thioacetamide, and $\mathrm{GO}$ as starting materials and hydriodic $\operatorname{acid}(\mathrm{HI})$ as reducing agent [111].

N-graphene's are also demonstrated to be promising as a new class of supporting materials [112-116]. Core/shell $\mathrm{Co}_{3} \mathrm{Sn}_{2} / \mathrm{Co} \mathrm{NPs}$, as a promising electrode material, have been grown on the $\mathrm{N}$-graphene through the hydrothermal process (Figure 5) [15]. First, N-graphene is prepared from GO by solvothermal method in the presence of $\mathrm{NH}_{3}$ and $\mathrm{NaOH}$. Then, $\mathrm{Co}_{2} \mathrm{SnO}_{4} \mathrm{NPs}_{\text {are }}$ deposited on $\mathrm{N}$-graphene by hydrothermal process from $\mathrm{SnCl}_{2} \cdot 5 \mathrm{H}_{2} \mathrm{O}$ and $\mathrm{CoCl}_{2} \cdot 6 \mathrm{H}_{2} \mathrm{O}$ in the presence of cetyltrimethyl ammonium bromide (CTAB). Finally, the annealing at $800^{\circ} \mathrm{C}$ for $1 \mathrm{~h}$ under reducing $\left(\mathrm{Ar} / \mathrm{H}_{2}\right)$ environment converts $\mathrm{Co}_{2} \mathrm{SnO}_{4}$ NPs to $\mathrm{Co}_{3} \mathrm{Sn}_{2} / \mathrm{Co}$ NPs. Similarly, Ngraphene-Ni ${ }_{3} \mathrm{~S}_{4} \mathrm{NPs}$ on $\mathrm{N}$-graphene sheets have been synthesized as a promising candidate for battery anode material (Figure 6a and 6b) [18]. The hydrothermal process can be further assisted by microwave for the production of novel graphene-NP composites. For example, microwave treatment of GO and manganese acetate and anhydrous hydrazine leads to the formation of a hierarchical hybrid of $\mathrm{Mn}_{3} \mathrm{O}_{4}$ embedded NPs in graphene sheets [117]. Direct growth of NPs on graphene can also be achieved via electrodeposition [118]. This has been demonstrated in preparing $\mathrm{MnO}_{2}$ NPs on graphene coated textile fiber as a novel electrode material (Figure 6c) [119]. In this process, the liquid exfoliated graphene sheets are initially coated on porous textile

fiber which serves as conductive 3D networks for subsequent controlled electrodeposition of $\mathrm{MnO}_{2} \mathrm{NPs}$ in a plating solution containing $\mathrm{Mn}\left(\mathrm{NO}_{3}\right)_{2}$ and $\mathrm{NaNO}_{3}$ at an applied deposition current of $0.1 \mathrm{~mA} / \mathrm{cm}^{2}$.

\subsubsection{Deposition of NPs on Graphene via Solution Phase Self-Assembly}


To control NP size and shape uniformity in the graphene-NP composites, it is better to prepare monodisperse NPs first and then assemble these NPs onto graphene. Due to the NP parameter controls, the properties of the graphene-NP composites can be better tuned by graphene-NP interactions. Recent synthetic advances have made it possible to prepare various NPs with controlled sizes, shapes, compositions and properties. Depending on the surfactant used in NP stabilization, these NPs are dispersible in a specific solvent. On the other hand, graphene has also been prepared to disperse in a suitable solvent. When two dispersions of NPs and graphene are mixed, surfactant exchange should lead to direct deposition of the monodisperse NPs on the graphene surface. Such solution phase based self-assembly process is advantageous compared to the direct growth of NPs on graphene, as monodisperse NPs are preformed and graphene-NP interaction can be tuned in a more rational way. One example is to assemble monodisperse FePt NPs on graphene [120]. In this process, monodisperse $7 \mathrm{~nm} \mathrm{FePt}$ NPs are synthesized by the simultaneous reduction of $\mathrm{Pt}(\mathrm{acac})_{2}(\mathrm{acac}=$ acetylacetonate $)$ and decomposition of $\mathrm{Fe}(\mathrm{CO})_{5}$ at $220^{\circ} \mathrm{C}$ in the presence of oleic acid $(\mathrm{OA})$ and oleylamine $(\mathrm{OAm})$. The oleate/oleylamine-coated FePt NPs are dispersed in hexane. In a separate synthesis, graphene is obtained from reduction of GO directly in DMF and dispersed in DMF. When the hexane dispersion of FePt NPs and the DMF solution of graphene are mixed and sonicated, FePt NPs are deposited on the graphene surface, giving graphene-FePt composites with FePt size, shape and composition well preserved (Figure 7a and 7b). To tight graphene-FePt connection, the as deposited composite may be baked at a controlled temperature. It should be noted that due to the flat surface on graphene, FePt NPs are not well stabilized; they tend to "roll" when the composite is baked, causing FePt NP to aggregate. To prevent FePt NP from aggregation, the temperature used to treat the composite should be lower than $200^{\circ} \mathrm{C}$. Using similar solution 
phase self-assembly, oleate-coated Co NPs are also deposited on graphene surface [121]. Once Co NPs are assembled, they can be oxidized in a more controlled process, giving graphene$\mathrm{Co} / \mathrm{CoO}$ composites with $\mathrm{CoO}$ layer tunable. Full $\mathrm{Co}$ oxidation gives graphene-CoO with $\mathrm{CoO}$ being in hollow structure.

\section{Applications of Graphene-NP Composites}

Among all promising energy storage and conversion devices studied for alternative energy applications, Li-based batteries, supercapacitors and fuel cells have attracted tremendous attention [122-126]. The basic structure of these devices includes two electrodes (cathode and anode), separator/electrolyte (permeable for ions but nonconductive to electrons). The performance of these devices mainly depends on the physical and chemical properties of their electrode materials. It is well known that nanostructures are advantageous over their counter microstructures due to their large surface area and high ionic diffusivities. However, these nanostructures are structurally disintegrated and often have low electronic conductivities, which are unsuitable for electrocatalysis [127-131]. Conductive carbons, represented by amorphous carbons, have been utilized extensively to improve the conductivity of the electrode materials [13, 132-135]. Recent developments in graphene chemistry and graphene-NP nanocomposites have made graphene an exciting new supporting material for energy storage and conversion applications in lithium ion battery (LIB), lithium sulfur battery (LSB), lithium air battery (LAB), supercapacitor (SC), oxygen reduction reaction (ORR), oxygen evolution reaction (OER), and hydrogen evolution reaction (HER) [28, 136-143].

\subsection{Lithium Batteries}

\subsubsection{Lithium Ion Battery (LIB)}


Introduced in 1991, LIB with a high energy density $(150 \mathrm{Wh} / \mathrm{kg})$ has become a major power source for today's mobile electronic devices [33]. In LIB, graphite is the universal choice of the anode material due to its $\mathrm{Li}$ storage capability (via $\mathrm{Li}$ intercalation between the graphitic layers). However, such a LIB is not suitable for powering electric vehicles due to its low capacity (theoretical value $372 \mathrm{mAh} / \mathrm{g}$ ) [144]. With each graphitic plane and $\pi$-electrons exposed, graphene is an ideal supporting materials for anode $[15,145]$ - Its large surface area can be used to store the high density of $\mathrm{Li}^{+}$; its mechanical toughness can help to endure the structural changes during the electrochemical reaction; and its excellent conductivity ensures the minimum ohmic loss during the discharge and charge reactions around the anode. The porosity of graphene can be further increased by photothermal treatment [145], which expands the stacking of the graphitic layers and produces micrometer scale pores, cracks, and voids for efficient $\mathrm{Li}^{+}$ intercalation kinetics even at higher charge-discharge rates.

$\mathrm{Co}_{3} \mathrm{~S}_{4}$ has been considered to be a promising anode material for LIB due to its high theoretical capacity of $702.8 \mathrm{mAh} / \mathrm{g}$. However, pure $\mathrm{Co}_{3} \mathrm{~S}_{4}$ suffers from capacity fading, low conductivity, and poor cyclability [146]. These are associated with the pulverization of electrodes, which results in the decay of the specific capacity and the formation of polysulfide anions. To overcome these problems, $\mathrm{Co}_{3} \mathrm{~S}_{4}$ nanotubes are made to deposit on graphene by using pre-synthesized $\mathrm{Co}(\mathrm{CO})_{0.35} \mathrm{Cl}_{0.20}(\mathrm{OH})_{1.10}$ nanowires and thioacetamide as sacrificial template and S source, respectively [19]. The composites show better cycling performance and higher reversible capacity than the pristine $\mathrm{Co}_{3} \mathrm{~S}_{4}$ electrode (Figure 8a). In this composite, graphene helps to preserve the structure of $\mathrm{Co}_{3} \mathrm{~S}_{4}$ while improving its conductivity and maintaining the ability to adsorb polysulfide anions. Heteroatom-doped graphene such as P-graphene can be used as LIB anodes due to the introduction of disordered carbon and lithium intercalated active sites 
in doping process [147]. Compared to graphene, in P-graphene, phosphorus doping not only increases the reversible discharge and charge capacity of graphene (460 vs. $280 \mathrm{mAh} / \mathrm{g}$ ) but also significantly improves its cyclic life and stability (Figure 8b) [147]. The doped graphene-NP composite as a LIB anode is better demonstrated in $\mathrm{N}$-graphene- $\mathrm{Ni}_{3} \mathrm{~S}_{4} \mathrm{NPs}$ [18]. Owing to its high theoretical capacity $(704.5 \mathrm{mAh} / \mathrm{g})$, safety and cost effectiveness, $\mathrm{Ni}_{3} \mathrm{~S}_{4}$ is a promising candidate for anode material in LIBs. The composite is made by hydrothermal reaction of $\mathrm{Ni}_{2}\left(\mathrm{CO}_{3}\right)(\mathrm{OH})_{2}$ and thioacetamide in the presence of $\mathrm{N}$-graphene at $200^{\circ} \mathrm{C}$ for $12 \mathrm{~h}$, in which $\mathrm{N}$ graphene is prepared by treating GO in ammonia solution and $\mathrm{NaOH}$. The N-graphene- $\mathrm{Ni}_{3} \mathrm{~S}_{4}$ composite shows higher reversible capacity (1323.2 vs. $494 \mathrm{mAh} / \mathrm{g})$ and much increased capacity retention ( 98.9 vs. $45.2 \%$ ) than the $\mathrm{Ni}_{3} \mathrm{~S}_{4}$ alone after 100 cycles at $0.2 \mathrm{C}$. The formation of thick solid electrolyte interphase (SEI) film, which causes the capacity loss in the initial cycles, can be significantly reduced by removing the oxygenated groups in GO via post thermal treatment.

Currently, group IV materials such as Si (4200 mAh/g), Ge (1600 mAh/g), and Sn (994 $\mathrm{mAh} / \mathrm{g}$ ) have received tremendous attention as a new generation of anode materials for LIB because of their high theoretical Li-storage capacities. However, these materials have low conductivity and are subject to a large volume change (up to 300\%) during Li uptake/release [148]. These expansion/contraction cycles generate the accumulated stresses in materials, resulting in fracture and battery capacity loss [149]. Strategies on structural design, morphology tuning, doping of inactive metals and coating with carbon have been explored to accommodate the volume changes $[15,133,148,150,151]$. Graphene can serve as an effective elastic buffer to relieve the accumulated strain. In one example, Ge/C core/shell NPs are coupled with graphene to minimize the mechanical stress induced by the volume change of $\mathrm{Ge}$ and to improve the 
conductivity of Ge (Figure 8c) [102]. This strategy is extended to rGO-Sn/C in wire-like structure by using void-engineering and leaving the space in between the carbon shell and Sn core to accommodate the volume changes of Sn (Figure 8d) [150]. However, Sn is not conductive enough and uncontrolled SEI film tends to be formed on the surface of the electrode. Recently, N-graphene is used to grow $\mathrm{Co}_{2} \mathrm{SnO}_{4} \mathrm{NPs}$ through hydrothermal process of $\mathrm{SnCl}_{2} \cdot 5 \mathrm{H}_{2} \mathrm{O}$ and $\mathrm{CoCl}_{6} \cdot \mathrm{H}_{2} \mathrm{O}$ in the presence of CTAB. By $800^{\circ} \mathrm{C}$ annealing under reducing $\left(\mathrm{Ar} / \mathrm{H}_{2}\right)$ environment, the $\mathrm{Co}_{2} \mathrm{SnO}_{4}$ NPs are converted into core/shell $\mathrm{Co}_{3} \mathrm{Sn}_{2} / \mathrm{Co}$ NPs (Figure 8e) [15]. The presence of Co shell around the Sn core helps to increase the Sn-core conductivity and structural stability. It also protects the direct interaction between Sn with electrolyte, preventing the formation of lithium dendrite structure around the electrode area, and controlling the thickness of SEI film. Furthermore, the elastically strong, flexible and conductive N-graphene overcoat can accommodate the volume changes, thus benefiting the structural and electrical stabilization of $\mathrm{Co}_{3} \mathrm{Sn}_{2} / \mathrm{Co}$ NPs. As a result, the $\mathrm{N}$-graphene-Co $\mathrm{Cn}_{2} / \mathrm{Co}$ displays a large reversible capacity (1615 mAh/g after 100 cycles), excellent capacity retention (102\%), high Columbic efficiency (nearly 100\%) and good rate capability (Figure 8f).

\subsubsection{Lithium Sulfur Battery (LSB)}

Sulfur is a promising cathode material in LSB due to its high theoretical capacity (1672 $\mathrm{mAh} / \mathrm{g}$ ), low price and natural abundance [152]. The LSB possess a high theoretical specific energy and volumetric energy densities of $2600 \mathrm{Wh} / \mathrm{kg}$ and $2800 \mathrm{Wh} / \mathrm{L}$, respectively [153]. Upon discharging, $\mathrm{S}$ reacts with Li by a two-electron reduction process to form polysulfide intermediates $\left(\mathrm{Li}_{2} \mathrm{~S}_{\mathrm{x}}, \mathrm{x}=2-8\right)$, and to generate $\mathrm{Li}_{2} \mathrm{~S}$ at the end of discharge. The major challenge facing LSB technology is the formation of the intermediate polysulfide anions which lower both 
electrical and $\mathrm{Li}^{+}$conductivities, affecting the battery performance [33] [154]. The cathode also suffers from large volume expansion ( $76 \%)$ during charging/discharging process.

One solution to overcome these challenges is to develop sulfur composite with porous materials like graphene that can adsorb polysulfide, increase the electrical conductivity and accommodate the structural change $[153,155]$. Graphene sheets incorporated with sulfur NPs (graphene-S) are fabricated by reducing $\mathrm{Na}_{2} \mathrm{~S}_{2} \mathrm{O}_{3} \cdot 5 \mathrm{H}_{2} \mathrm{O}$ on graphene sheets and the composite electrode has the capacity retention rate of $83 \%$ and energy density of $804 \mathrm{Wh} / \mathrm{kg}$ after 100 cycles [156]. However, the polysulfide anions still tend to move across the cell due to the open end of graphene. Recently, the activated graphene sheets with dense nanopores are synthesized via chemical activation of hydrothermally reduced GO hydrogel with $\mathrm{KOH}$ and used as scaffolds for confining sulfur NPs in LSB [157]. The graphene-S composites show high reversible specific capacities up to $1379 \mathrm{mAh} / \mathrm{g}$ and good cycling stabilities. Here the highly porous graphene framework acts not only as an electronic conductor, but also as a trap to hold polysulfides and accommodate the volume expansion during charge/discharge process. Furthermore, sulfur NPs can be wrapped by graphene and polyethylene glycol (PEG) to overcome the polysulfide dissolution, to accommodate volume expansion, and to improve the conductivity (Figure 9a and 9b) [158]. This new composite has shown high and stable specific capacities up to $\sim 600 \mathrm{mAh} / \mathrm{g}$ over more than 100 cycles (Figure 9c).

\subsubsection{Lithium-Air Battery (LAB)}

Unlike traditional LIBs, LABs abandon the intercalation mechanism and allows Li to react directly with $\mathrm{O}_{2}$ from air at cathodes to form discharge products, mainly $\mathrm{Li}_{2} \mathrm{O}_{2}$. As a result, the unique battery chemistry and electrode architecture provide a greatly increased specific energy density (theoretical value of $5200 \mathrm{Wh} / \mathrm{kg}$ ), holding promise to meet the energy density targets set 
for batteries in automotive applications $(1700 \mathrm{Wh} / \mathrm{kg}$, a value comparable to the usable energy content of gasoline) [159-165]. Electrocatalysts with low ORR (discharge)/OER (charge) overpotentials and optimal electrode structures are critical to improving the power density and cycling capability of LABs [166-168]. Due to their good ORR/OER activity, graphene-based materials are viewed as ideal candidates for cathodes in LABs. N-graphene sheets prepared by heating graphene sheets under ammonia mixed with $\mathrm{Ar}$ at $900^{\circ} \mathrm{C}$ have an initial discharge capacity of $11660 \mathrm{mAh} / \mathrm{g}$ in a non-aqueous LAB, which is significantly higher than that of the graphene sheets $(8530 \mathrm{mAh} / \mathrm{g})$ [169]. This demonstrates that, like in aqueous solution, nitrogen doping to graphene can also efficiently enhance the ORR activity in non-aqueous electrolyte (typically $\mathrm{LiPF}_{6}$ in tetraethylene glycol dimethyl ether) and serve as promising cathode materials for LABs. Graphene have also been employed to fabricate composite catalysts with transition metal oxides such as $\mathrm{MnO}_{\mathrm{x}}$, which are extensively studied catalysts for LABs but suffer from low electrical conductivity [170]. The rGO- $\mathrm{Mn}_{3} \mathrm{O}_{4}$ nanocomposites has been developed by adding $\mathrm{Mn}(\mathrm{Ac})_{2} \cdot 4 \mathrm{H}_{2} \mathrm{O}$ into $\mathrm{rGO}$ suspension in the presence of $\mathrm{KOH}-\mathrm{C}_{2} \mathrm{H}_{5} \mathrm{OH}$ for the LAB cathode (Figure 10a and 10b) [171]. This in-situ growth results in a strong covalent bonding between $\mathrm{Mn}_{3} \mathrm{O}_{4}$ and $\mathrm{rGO}$, leading to a superior performance in LABs with an exceptionally high initial discharge capacity of $16000 \mathrm{mAh} / \mathrm{g}$ (Figure 10c and 10d).

\subsection{Supercapacitor (SC)}

Supercapacitors (SCs) are electrochemical energy storage devices that store and release energy by reversible adsorption and desorption of ions at the interfaces between electrode materials and electrolytes. One common type of SCs is electrochemical double layer capacitors (EDLCs) that store energy by accumulation of charges in the electrical double layer via electrostatic interactions at the electrode-electrolyte interface [172]. Physical accumulation of 
ions via electrostatic interaction required large surface, thus carbon based materials such as graphene are favorable as electrodes for EDLCs [173-175]. For instance, using microwave exfoliation and $\mathrm{KOH}$ activation, a porous microwave exfoliated GO with a Brunauer-EmmettTeller (BET) surface area of up to $3100 \mathrm{~m}^{2} / \mathrm{g}$ has been synthesized. Two-electrode SC cells constructed with this activated GO yields excellent gravimetric capacitance $(150 \mathrm{~F} / \mathrm{g})$ and energy density $(\sim 70 \mathrm{Wh} / \mathrm{kg})$ with organic and ionic liquid electrolytes, which are significantly higher than that from the conventional carbon materials. Heteroatom-doped graphene have also been explored as SC electrodes [176]. B-graphene is developed by reduction of GO with a borane $\left(\mathrm{BH}_{3}\right)$-tetrahydrofuran (THF) adduct under reflux to improve the interfacial capacitance of graphene through effecting the electronic structure and density of state (DOS) [177].

The second common type of SC is pseudo-capacitors which store energy via Faradaic redox reaction at electrode surface with enhanced capacitance [178]. The electronically conducting polymers, metals oxides and hydroxides are promising electrode materials because they are able to increase specific capacitance via pseudo-capacitive redox reactions [131, 179]. However, the low electrical conductivity, poor compatibility with organic electrolytes, and short cycle life have limited the practical application of these pseudo-capacitive materials. $\mathrm{Ni}(\mathrm{OH})_{2}$ has been deposited on 3D graphene to improve the performance and stability of $\mathrm{Ni}(\mathrm{OH})_{2}$, as $3 \mathrm{D}$ graphene can enlarge the surface area of electrode, resulting in better electrode-electrolyte contact and enhancing the conductivity of ions and electrons [180].

\subsection{Oxygen Reduction Reaction (ORR)}

Electrochemical reduction of oxygen is an important reaction for electrochemical devices directly related to efficient energy conversion and storage, such as fuel cells, metal-air batteries, and electrolyzers [181]. Generally, a direct four-electron reduction of oxygen to $\mathrm{H}_{2} \mathrm{O}$ is more 
efficient and desired compared to two-electron reduction which leads to the formation of $\mathrm{H}_{2} \mathrm{O}_{2}$. On the state-of-the-art Pt catalysts, ORR proceeds via the four-electron reduction. Due to its large surface area, excellent conductivity and stability, graphene has been explored extensively as non-precious metal catalysts for ORR [182-186]. Generally, the application of graphene-based catalysts towards ORR can be categorized into three groups: metal-free heteroatom-doped graphene materials, graphene/non-precious metals hybrid materials, and graphene/noble metal NP composites. As discussed in Section 3, heteroatoms doping, especially N-doping, can tune the electronic and geometric properties and induce the defects into graphene structure, thereby facilitating ORR. N-graphene prepared by CVD of methane in the presence of ammonia is first tested for ORR in alkaline media [62]. Following this pioneering work, a great number of methods have been reported to develop metal-free heteroatom-doped graphene catalysts for ORR $[86,187]$. In the meantime, several ORR mechanisms on N-graphene have been proposed [70, 71] and theoretical calculations indicate that $\mathrm{C}$ atoms near the doped $\mathrm{N}$ can serve as active sites for the four-electron reduction of oxygen to water (Figure $4 \mathbf{b}$ ).

Although catalysts with respectable ORR activity can be prepared without any detectable metal content, so far the presence of metals still affords catalysts with higher activity and better durability compared to metal-free catalysts. A large variety of graphene-NP composite catalysts have been developed by hydrothermal/solvothermal or self-assembly methods as efficient ORR catalysts in alkaline media, including $\mathrm{N}-\mathrm{rGO}-\mathrm{Co}_{3} \mathrm{O}_{4}$ [188], N-rGO- $\mathrm{MnCo}_{2} \mathrm{O}_{4}$ [189], $\mathrm{rGO}-\mathrm{Co}_{1-x} \mathrm{~S}$ [190], N-rGO-CoO [191], graphene-Co/CoO [121]. Although the newly-developed graphenebased composites have demonstrated superior ORR activity and durability to that of commercial carbon supported Pt (C-Pt) catalysts in alkaline solution [163, 186, 192, 193], these non-Pt catalysts cannot compete with C-Pt catalysts in acidic environments [67, 194]. Therefore, Pt- 
based NPs are still studied as the most promising catalysts for Nafion ${ }^{\circledR}$-based polymer electrolyte fuel cells (PEFCs) [195-200]. Especially, the introduction of transition metals into Pt can adjust the $d$-band center and tune the binding energy of adsorbed oxygenated species, thereby facilitating the ORR [196]. Recently, a solution-phase self-assembly method is used to deposit monodisperse $7 \mathrm{~nm} \mathrm{FePt} \mathrm{NPs} \mathrm{on} \mathrm{the} \mathrm{graphene} \mathrm{surface,} \mathrm{giving} \mathrm{graphene-FePt} \mathrm{(Figure} \mathrm{7b)} \mathrm{[120].}$ The ORR activity measured with the graphene-FePt in $0.1 \mathrm{M} \mathrm{HClO}_{4}$ solution is improved relative to that on C-FePt and commercial C-Pt catalysts (Figure 7c and 7d), indicating the promotional effect of graphene as a supporting materials on FePt catalysis.

\subsection{Oxygen Evolution Reaction (OER)}

Oxygen evolution reaction (OER) is opposite reaction to ORR and is often used to couple with other reactions in a number of key renewable energy systems, such as solar cells, metal-air batteries, and electrochemical water splitting $[68,201]$. Similar to ORR, OER is also kinetically sluggish, and free binding energy between $\mathrm{O}^{*}$ and $\mathrm{OH}^{*}$ has been introduced as a catalytic descriptor to understand OER process [202]. It is believed that a moderate binding energy of the OER intermediates is necessary for the catalyst to show high activity [203]. The state-of-the-art OER catalysts consist of precious metals such as $\mathrm{IrO}_{2}$ or $\mathrm{RuO}_{2}$ [204]. Therefore, advanced OER catalysts made from earth-abundant elements with sufficient activity and stability are highly desired. Graphene or N-graphene have been employed to couple with metal NPs to enhance OER activity [205]. For example, N-graphene film-Ni NP composite prepared by reducing $\mathrm{Ni}\left(\mathrm{NO}_{3}\right)_{2} \cdot 6 \mathrm{H}_{2} \mathrm{O}$ and doping $\mathrm{N}$ into graphene (via hydrazine hydrate) in a solvothermal process shows comparable OER overpotentials in alkaline solution with the commercial $\mathrm{IrO}_{2}$ catalysts [206]. To date, the OER electrocatalysis is still far less explored relative to ORR and criteria employed to evaluate oxygen-evolving catalysts are not standardized. 


\subsection{Hydrogen Evolution Reaction (HER)}

Electrocatalytic water splitting to produce hydrogen has attracted considerable attention owing to its great potential in providing green and sustainable source of energy. Currently, the major challenge facing HER electrocatalyst is the poor stability of the catalysts. Nanostructures instead of microstructures, along with addition of carbon are efficient and useful solutions to enhance the catalyst lifetime. In last decade, many types of nanosized HER electrocatalysts have been developed [207, 208]. However, aggregation and deactivation during the reaction process remain the major problems hindering the activity and stability of these catalysts. It is found that the combination of graphene with traditional NP catalysts can greatly improve the catalyst performance for HER.

A large number of graphene-based catalysts for electrolysis of water have been developed to enhance the energy conversion efficiency from electricity to hydrogen molecules. Currently the C-Pt is the-state-of-the-art catalyst and nanostructured $\mathrm{MoS}_{2}$ catalysts have been demonstrated as the most promising non-Pt catalysts for HER [209]. The composite of $\mathrm{rGO}-\mathrm{MoS}_{2} \mathrm{NPs}$ can be prepared by a solvothermal reaction of $\left(\mathrm{NH}_{4}\right)_{2} \mathrm{MoS}_{4}$ and hydrazine in DMF solution of GO [210]. Compared with the individual $\mathrm{MoS}_{2}$ and $\mathrm{rGO}$, the $\mathrm{rGO}-\mathrm{MoS}_{2}$ exhibits low overpotential and small Tafel slopes in HER, owing to intense electronic and chemical coupling between rGO and $\mathrm{MoS}_{2}$ (Figure 11). Recently, the composite of $\mathrm{N}$-graphene-carbon nitride are also obtained by annealing dicyandiamide and $\mathrm{GO}$ at $600^{\circ} \mathrm{C}$. It shows an unexpected HER activity with overpotential and Tafel slope comparable to the $\mathrm{MoS}_{2}$-based catalysts [211].

\section{Graphene-Based Composite Catalysts for Other Reactions}

Graphene-based composite catalysts have also been explored to catalyze many other types of reactions. Here we only highlight a few of them that are important for energy applications. 
The graphene-NP composite catalysts have been used to convert solar energy into chemical energy by splitting water into hydrogen photocatalytically. For example, $\mathrm{rGO}-\mathrm{Zn}_{\mathrm{x}} \mathrm{Cd}_{1-\mathrm{x}} \mathrm{S}$ exhibits a fast $\mathrm{H}_{2}$ production rate of $1824 \mu \mathrm{mol} / \mathrm{hg}$ and excellent quantum efficiency of $23.4 \%$ under a $420 \mathrm{~nm}$ solar irradiation, superior to that of the pristine $\mathrm{Zn}_{0.8} \mathrm{Cd}_{0.2}$ photocatalyst [212]. The $\mathrm{N}$ graphene is used to enhance HER catalytic performance of a Si photocathode, which shows high activity and long stability in both acidic and neutral environment for solar driven HER [213]. The $\alpha-\mathrm{Fe}_{2} \mathrm{O}_{3} /$ graphene/ $\mathrm{BiV}_{1-\mathrm{x}} \mathrm{Mo}_{\mathrm{x}} \mathrm{O} 4$ core/shell aligned nanorod arrays are tested as novel photoelectrochemical catalysts for water splitting with much improved separation of photocarriers at the interface of $\alpha-\mathrm{Fe}_{2} \mathrm{O}_{3}$ nanorod/graphene/ $\mathrm{BiV}_{1-\mathrm{x}} \mathrm{Mo}_{\mathrm{x}} \mathrm{O}_{4}$ heterojunction [214].

Graphene based composites can be used as photocatalysts to reduce $\mathrm{CO}_{2}$ into reactive carbon forms. For example, when the hollow $\mathrm{Ti}_{0.91} \mathrm{O}_{2}$ is coupled with graphene via layer-by-layer assembly method, the composite shows extraordinary photocatalytic performance for $\mathrm{CO}_{2}$ conversion into $\mathrm{CO}$ and $\mathrm{CH}_{4}$ [215]. In this enhanced catalysis, the tight stacking between the ultrathin $\mathrm{Ti}_{0.91} \mathrm{O}_{2}$ and graphene is critical to increase photogenerated electron transfer rate and to further improve the lifetime of charge carriers. Graphene-Cu NP composite is found to be active photocatalyst for transforming aromatic nitro compounds into azoxy or azo compounds [216], providing a green photocatalytic route for the reduction of aromatic nitro compounds into other important organic molecules. In the composite, the carbon vacancies or dangling bonds in graphene influences the electronic structure of $\mathrm{Cu}$ and improves its chemical stability while the excited electrons on the surface of the $\mathrm{Cu}$ NPs facilitate the cleavage of the N-O bonds in the aromatic nitro compounds.

\section{Conclusions}


Thanks to its unique chemical structure and excellent conductivity, transparency, mechanical strength, porosity and electrochemical properties, graphene has been extensively studied for various applications, especially for electrochemical energy conversion and storage. To fulfill the increasing demands of graphene, several synthesis methods have been explored in terms of the quality, mass production and cost. Presently, research has been focused on the well-controlled synthesis of graphene with optimum property, targeting to the specific applications. The doping of the heteroatoms further tunes the electrochemical properties of graphene via changing the electronic structure and density of state. To date, a large variety of metal NP catalysts have been developed to improve the performance of energy-related devices and reactions, such as LIB, Li$\mathrm{O}_{2}$ battery, LSB, SCs, ORR, OER, and HER. The combination of graphene or doped-graphene with NPs is found to significantly enhance the performance by stabilizing the NPs and enhancing the electrical conductivity. To develop highly-efficient graphene-based catalysts and/or electrode materials, one must first optimize the synthesis strategy to improve the yield and quality of graphene and doped-graphene. The doped-graphene should have heteroatoms located on specific sites. The optimized graphene or doped-graphene will allow rational assembly of NPs on the graphitic surface and graphene-NP interaction should be tunable to achieve the desired synergistic effect for highly efficient electrochemical energy applications.

\section{Acknowledgements}

Work at Brown was supported in part by the U.S. Department of Energy, Office of Energy Efficiency and Renewable Energy, the Fuel Cell Technologies Program, by the U.S. Army Research Laboratory and the U.S. Army Research Office under the Multi University Research Initiative MURI (W911NF-11-1-0353) on "Stress-Controlled Catalysis via Engineered 
Nanostructures"; work in Peking University was supported by the NSFC-RGC Joint Research

Scheme (51361165201), NSFC (51125001, 51172005), Beijing Natural Science Foundation

(2122022), Aerostatic Science Foundation (2010ZF71003), and Doctoral Program of the

Ministry of Education of China (20120001110078).

\section{References}

[1] X. Huang, Z.Y. Yin, S.X. Wu, X.Y. Qi, Q.Y. He, Q.C. Zhang, Q.Y. Yan, F. Boey, H. Zhang, Small 7 (2011) 1876.

[2] N.O. Weiss, H. Zhou, L. Liao, Y. Liu, S. Jiang, Y. Huang, X. Duan, Adv Mater 24 (2012) 5782.

[3] A.A. Green, M.C. Hersam, J Phys Chem Lett 1 (2010) 544.

[4] A.H. Castro Neto, N.M.R. Peres, K.S. Novoselov, A.K. Geim, Reviews of Modern Physics 81 (2009) 109.

[5] Y. Zhang, Y.-W. Tan, H.L. Stormer, P. Kim, Nature 438 (2005) 201.

[6] M.S. Fuhrer, C.N. Lau, A.H. MacDonald, MRS Bull. 35 (2010) 289.

[7] K.I. Bolotin, K.J. Sikes, Z. Jiang, M. Klima, G. Fudenberg, J. Hone, P. Kim, H.L. Stormer, Solid State Commun. 146 (2008) 351.

[8] X. Du, I. Skachko, A. Barker, E.Y. Andrei, Nat Nanotechnol 3 (2008) 491.

[9] A.A. Balandin, Nat Mater 10 (2011) 569.

[10] I.W. Frank, D.M. Tanenbaum, A.M. van der Zande, P.L. McEuen, Journal of Vacuum Science \&amp; Technology B 25 (2007) 2558.

[11] R.P. Ojha, P.A. Lemieux, P.K. Dixon, A.J. Liu, D.J. Durian, Nature 427 (2004) 521.

[12] M.D. Stoller, S. Park, Y. Zhu, J. An, R.S. Ruoff, Nano Lett. 8 (2008) 3498.

[13] Y. Zou, Y. Wang, ACS Nano 5 (2011) 8108.

[14] K. Liu, L. Liu, Y. Luo, D. Jia, J. Mater. Chem. 22 (2012) 20342.

[15] N. Mahmood, C. Zhang, F. Liu, J. Zhu, Y. Hou, ACS Nano 7 (2013) 10307.

[16] Z. Du, X. Yin, M. Zhang, Q. Hao, Y. Wang, T. Wang, Mater. Lett. 64 (2010) 2076.

[17] J. Chang, M. Jin, F. Yao, T.H. Kim, V.T. Le, H. Yue, F. Gunes, B. Li, A. Ghosh, S. Xie, Y.H. Lee, Adv. Funct. Mater. 23 (2013) 5074.

[18] N. Mahmood, C.Z. Zhang, Y.L. Hou, Small 9 (2013) 1321.

[19] N. Mahmood, C.Z. Zhang, J. Jiang, F. Liu, Y.L. Hou, Chem-Eur J 19 (2013) 5183.

[20] Y.N. Meng, K. Wang, Y.J. Zhang, Z.X. Wei, Adv Mater 25 (2013) 6985.

[21] X. Huang, Z.Y. Zeng, Z.X. Fan, J.Q. Liu, H. Zhang, Adv Mater 24 (2012) 5979.

[22] C.H. Xu, B.H. Xu, Y. Gu, Z.G. Xiong, J. Sun, X.S. Zhao, Energ Environ Sci 6 (2013) 1388.

[23] Z. Yang, Z. Yao, G. Li, G. Fang, H. Nie, Z. Liu, X. Zhou, X.a. Chen, S. Huang, ACS Nano 6 (2012) 205.

[24] J. Xu, G. Dong, C. Jin, M. Huang, L. Guan, ChemSusChem 6 (2013) 493.

[25] C.N.R. Rao, H.S.S.R. Matte, K.S. Subrahmanyam, Acc. Chem. Res. 46 (2013) 149.

[26] C. Venkateswara Rao, A. Leela Mohana Reddy, Y. Ishikawa, P.M. Ajayan, ACS Appl Mater Interfaces 3 (2011) 2966.

[27] Z.-L. Wang, D. Xu, H.-G. Wang, Z. Wu, X.-B. Zhang, ACS Nano 7 (2013) 2422. 
[28] Y. Sun, Q. Wu, G. Shi, Energy Environ. Sci. 4 (2011) 1113.

[29] M. Gong, Y. Li, H. Wang, Y. Liang, J.Z. Wu, J. Zhou, J. Wang, T. Regier, F. Wei, H. Dai, J. Am. Chem. Soc. 135 (2013) 8452.

[30] S. Bae, H. Kim, Y. Lee, X. Xu, J.-S. Park, Y. Zheng, J. Balakrishnan, T. Lei, H. Ri

Kim, Y.I. Song, Y.-J. Kim, K.S. Kim, B. Ozyilmaz, J.-H. Ahn, B.H. Hong, S. lijima, Nat Nano 5 (2010) 574.

[31] Y. Yang, A.M. Asiri, Z. Tang, D. Du, Y. Lin, Mater. Today 16 (2013) 365.

[32] K.C. Kemp, H. Seema, M. Saleh, N.H. Le, K. Mahesh, V. Chandra, K.S. Kim, Nanoscale 5 (2013) 3149.

[33] N. Mahmood, C. Zhang, H. Yin, Y. Hou, Journal of Materials Chemistry A 2 (2014) 15.

[34] K.S. Novoselov, V.I. Falko, L. Colombo, P.R. Gellert, M.G. Schwab, K. Kim, Nature 490 (2012) 192.

[35] Y. Hernandez, V. Nicolosi, M. Lotya, F.M. Blighe, Z. Sun, S. De, I.T. McGovern, B. Holland, M. Byrne, Y.K. Gun'ko, J.J. Boland, P. Niraj, G. Duesberg, S. Krishnamurthy, R. Goodhue, J. Hutchison, V. Scardaci, A.C. Ferrari, J.N. Coleman, Nat. Nanotechnol. 3 (2008) 563.

[36] X. Cui, C.Z. Zhang, R. Hao, Y.L. Hou, Nanoscale 3 (2011) 2118.

[37] J.N. Coleman, Accounts Chem Res 46 (2013) 14.

[38] V. Leon, A.M. Rodriguez, P. Prieto, M. Prato, E. Vazquez, Acs Nano 8 (2014) 563.

[39] J.N. Coleman, Adv Funct Mater 19 (2009) 3680.

[40] S. Bae, H. Kim, Y. Lee, X.F. Xu, J.S. Park, Y. Zheng, J. Balakrishnan, T. Lei, H.R. Kim, Y.I. Song, Y.J. Kim, K.S. Kim, B. Ozyilmaz, J.H. Ahn, B.H. Hong, S. lijima, Nat Nanotechnol 5 (2010) 574.

[41] D.A.C. Brownson, C.E. Banks, Phys Chem Chem Phys 14 (2012) 8264.

[42] Y. Zhang, L.Y. Zhang, P. Kim, M.Y. Ge, Z. Li, C.W. Zhou, Nano Lett 12 (2012) 2810.

[43] H.L. Zhou, W.J. Yu, L.X. Liu, R. Cheng, Y. Chen, X.Q. Huang, Y. Liu, Y. Wang, Y. Huang, X.F. Duan, Nat Commun 4 (2013)

[44] Y. Zhang, L.Y. Zhang, C.W. Zhou, Accounts Chem Res 46 (2013) 2329.

[45] C. Mattevi, H. Kim, M. Chhowalla, J Mater Chem 21 (2011) 3324.

[46] G.H. Lee, R.C. Cooper, S.J. An, S. Lee, A. van der Zande, N. Petrone, A.G. Hammerherg, C. Lee, B. Crawford, W. Oliver, J.W. Kysar, J. Hone, Science 340 (2013) 1073.

[47] M. Cai, D. Thorpe, D.H. Adamson, H.C. Schniepp, J. Mater. Chem. 22 (2012) 24992.

[48] A. Ciesielski, P. Samori, Chem Soc Rev 43 (2014) 381.

[49] C.-Y. Su, A.-Y. Lu, Y. Xu, F.-R. Chen, A.N. Khlobystov, L.-J. Li, ACS Nano 5 (2011) 2332.

[50] W. Qian, X. Cui, R. Hao, Y. Hou, Z. Zhang, ACS Appl Mater Interfaces 3 (2011) 2259.

[51] C. Wu, Q. Cheng, K.B. Wu, G. Wu, Q. Li, Anal Chim Acta 825 (2014) 26.

[52] D. Nuvoli, L. Valentini, V. Alzari, S. Scognamillo, S.B. Bon, M. Piccinini, J. Illescas, A. Mariani, J. Mater. Chem. 21 (2011) 3428.

[53] W. Qian, R. Hao, Y. Hou, Y. Tian, C. Shen, H. Gao, X. Liang, Nano Res. 2 (2009) 706.

[54] X. Li, X. Wang, L. Zhang, S. Lee, H. Dai, Science 319 (2008) 1229. 
[55] D. Parviz, S. Das, H.S.T. Ahmed, F. Irin, S. Bhattacharia, M.J. Green, Acs Nano 6 (2012) 8857.

[56] R. Hao, W. Qian, L. Zhang, Y. Hou, Chem Commun (Camb) (2008) 6576.

[57] U. Khan, A. O'Neill, M. Lotya, S. De, J.N. Coleman, Small 6 (2010) 864.

[58] U. Khan, A. O'Neill, H. Porwal, P. May, K. Nawaz, J.N. Coleman, Carbon 50 (2012) 470.

[59] C.K. Chua, M. Pumera, Chem Soc Rev 43 (2014) 291.

[60] C.K. Chua, M. Pumera, Chem Soc Rev 43 (2014) 291.

[61] K.P. Gong, F. Du, Z.H. Xia, M. Durstock, L.M. Dai, Science 323 (2009) 760.

[62] L.T. Qu, Y. Liu, J.B. Baek, L.M. Dai, Acs Nano 4 (2010) 1321.

[63] C.N.R. Rao, K. Gopalakrishnan, A. Govindaraj, Nano Today 9 (2014) 324.

[64] S.U. Lee, R.V. Belosludov, H. Mizuseki, Y. Kawazoe, Small 5 (2009) 1769.

[65] J.R. Pels, F. Kapteijn, J.A. Moulijn, Q. Zhu, K.M. Thomas, Carbon 33 (1995) 1641.

[66] G. Wu, C. Dai, D. Wang, D. Li, N. Li, J. Mater. Chem. 20 (2010) 3059.

[67] G. Wu, K.L. More, C.M. Johnston, P. Zelenay, Science 332 (2011) 443.

[68] Y. Zhao, R. Nakamura, K. Kamiya, S. Nakanishi, K. Hashimoto, Nat Commun 4 (2013)

[69] B. Kumar, M. Asadi, D. Pisasale, S. Sinha-Ray, B.A. Rosen, R. Haasch, J. Abiade, A.L. Yarin, A. Salehi-Khojin, Nat Commun 4 (2013)

[70] L.P. Zhang, Z.H. Xia, J Phys Chem C 115 (2011) 11170.

[71] R.A. Sidik, A.B. Anderson, N.P. Subramanian, S.P. Kumaraguru, B.N. Popov, J Phys Chem B 110 (2006) 1787.

[72] Y.Z. Xue, B. Wu, L. Jiang, Y.L. Guo, L.P. Huang, J.Y. Chen, J.H. Tan, D.C. Geng, B.R. Luo, W.P. Hu, G. Yu, Y.Q. Liu, J Am Chem Soc 134 (2012) 11060.

[73] X.L. Li, H.L. Wang, J.T. Robinson, H. Sanchez, G. Diankov, H.J. Dai, J Am Chem Soc 131 (2009) 15939.

[74] D.S. Geng, Y. Chen, Y.G. Chen, Y.L. Li, R.Y. Li, X.L. Sun, S.Y. Ye, S. Knights, Energ Environ Sci 4 (2011) 760.

[75] L.S. Panchokarla, K.S. Subrahmanyam, S.K. Saha, A. Govindaraj, H.R. Krishnamurthy, U.V. Waghmare, C.N.R. Rao, Adv Mater 21 (2009) 4726.

[76] Y.Y. Shao, S. Zhang, M.H. Engelhard, G.S. Li, G.C. Shao, Y. Wang, J. Liu, I.A. Aksay, Y.H. Lin, J Mater Chem 20 (2010) 7491.

[77] H.M. Jeong, J.W. Lee, W.H. Shin, Y.J. Choi, H.J. Shin, J.K. Kang, J.W. Choi, Nano Lett 11 (2011) 2472.

[78] Y.Y. Liang, Y.G. Li, H.L. Wang, J.G. Zhou, J. Wang, T. Regier, H.J. Dai, Nat Mater $10(2011) 780$.

[79] C.Z. Zhang, R. Hao, H.B. Liao, Y.L. Hou, Nano Energy 2 (2013) 88.

[80] Z.H. Sheng, L. Shao, J.J. Chen, W.J. Bao, F.B. Wang, X.H. Xia, Acs Nano 5 (2011) 4350.

[81] K. Parvez, S.B. Yang, Y. Hernandez, A. Winter, A. Turchanin, X.L. Feng, K. Mullen, Acs Nano 6 (2012) 9541.

[82] Z.Y. Lin, G. Waller, Y. Liu, M.L. Liu, C.P. Wong, Adv Energy Mater 2 (2012) 884.

[83] L.J. Yang, S.J. Jiang, Y. Zhao, L. Zhu, S. Chen, X.Z. Wang, Q. Wu, J. Ma, Y.W. Ma, Z. Hu, Angew Chem Int Edit 50 (2011) 7132.

[84] L.R. Radovic, M. Karra, K. Skokova, P.A. Thrower, Carbon 36 (1998) 1841. 
[85] J. Han, L.L. Zhang, S. Lee, J. Oh, K.S. Lee, J.R. Potts, J.Y. Ji, X. Zhao, R.S. Ruoff, S. Park, Acs Nano 7 (2013) 19.

[86] D.W. Wang, D.S. Su, Energy Environ. Sci. 7 (2014) 576.

[87] I. Herrmann, U.I. Kramm, J. Radnik, S. Fiechter, P. Bogdanoff, J Electrochem Soc 156 (2009) B1283.

[88] S.A. Wohlgemuth, R.J. White, M.G. Willinger, M.M. Titirici, M. Antonietti, Green Chemistry 14 (2012) 1515.

[89] S.B. Yang, L.J. Zhi, K. Tang, X.L. Feng, J. Maier, K. Mullen, Adv Funct Mater 22 (2012) 3634.

[90] H.T. Chung, C.M. Johnston, K. Artyushkova, M. Ferrandon, D.J. Myers, P. Zelenay, Electrochem. Commun. 12 (2010) 1792.

[91] J. Liang, Y. Jiao, M. Jaroniec, S.Z. Qiao, Angew Chem Int Edit 51 (2012) 11496.

[92] W.G. Feng, E. Borguet, R.D. Vidic, Carbon 44 (2006) 2998.

[93] Z. Yang, Z. Yao, G.F. Li, G.Y. Fang, H.G. Nie, Z. Liu, X.M. Zhou, X. Chen, S.M. Huang, Acs Nano 6 (2012) 205.

[94] M. Seredych, T.J. Bandosz, Carbon 66 (2014) 227.

[95] X.K. Kong, Q.W. Chen, Z.Y. Sun, Chemphyschem 14 (2013) 514.

[96] R. Li, Z.D. Wei, X.L. Gou, W. Xu, Rsc Adv 3 (2013) 9978.

[97] Z.W. Liu, F. Peng, H.J. Wang, H. Yu, J. Tan, L.L. Zhu, Catal. Commun. 16 (2011) 35.

[98] V.V. Strelko, Journal of Energy Chemistry 22 (2013) 174.

[99] S.Y. Wang, L.P. Zhang, Z.H. Xia, A. Roy, D.W. Chang, J.B. Baek, L.M. Dai, Angew Chem Int Edit 51 (2012) 4209.

[100] C.H. Choi, S.H. Park, S.I. Woo, Acs Nano 6 (2012) 7084.

[101] B. Luo, B. Wang, X. Li, Y. Jia, M. Liang, L. Zhi, Adv Mater 24 (2012) 3538.

[102] D.-J. Xue, S. Xin, Y. Yan, K.-C. Jiang, Y.-X. Yin, Y.-G. Guo, L.-J. Wan, J. Am. Chem. Soc. 134 (2012) 2512.

[103] G. Giovannetti, P.A. Khomyakov, G. Brocks, V.M. Karpan, J. van den Brink, P.J. Kelly, Phys Rev Lett 101 (2008)

[104] P.A. Khomyakov, A.A. Starikov, G. Brocks, P.J. Kelly, Phys Rev B 82 (2010)

[105] C.J. Shearer, A. Cherevan, D. Eder, Adv. Mater. (2014) n/a.

[106] S. Xin, Y.G. Guo, L.J. Wan, Accounts Chem Res 45 (2012) 1759.

[107] H.L. Wang, H.J. Dai, Chem Soc Rev 42 (2013) 3088.

[108] Y.Y. Liang, Y.G. Li, H.L. Wang, H.J. Dai, J Am Chem Soc 135 (2013) 2013.

[109] M.M. Liu, R.Z. Zhang, W. Chen, Chem. Rev. 114 (2014) 5117.

[110] M.R. Gao, Y.F. Xu, J. Jiang, S.H. Yu, Chem Soc Rev 42 (2013) 2986.

[111] J. Jiang, Y. Feng, N. Mahmood, F. Liu, Y.L. Hou, Sci Adv Mater 5 (2013) 1667.

[112] Y.Y. Zhao, Y.K. Zhou, R. O'Hayre, Z.P. Shao, J Phys Chem Solids 74 (2013) 1608.

[113] Y.Y. Zhao, Y.K. Zhou, B. Xiong, J. Wang, X. Chen, R. O'Hayre, Z.P. Shao, J Solid State Electr 17 (2013) 1089.

[114] B. Xiong, Y.K. Zhou, R. O'Hayre, Z.P. Shao, Appl Surf Sci 266 (2013) 433.

[115] B. Xiong, Y.K. Zhou, Y.Y. Zhao, J. Wang, X. Chen, R. O'Hayre, Z.P. Shao, Carbon 52 (2013) 181.

[116] Y.K. Zhou, K. Neyerlin, T.S. Olson, S. Pylypenko, J. Bult, H.N. Dinh, T. Gennett, Z.P. Shao, R. O'Hayre, Energy Environ. Sci. 3 (2010) 1437.

[117] L. Li, Z. Guo, A. Du, H. Liu, J. Mater. Chem. 22 (2012) 3600. 
[118] N. Tian, Z.Y. Zhou, S.G. Sun, Y. Ding, Z.L. Wang, Science 316 (2007) 732.

[119] G.H. Yu, L.B. Hu, M. Vosgueritchian, H.L. Wang, X. Xie, J.R. McDonough, X. Cui, Y. Cui, Z.N. Bao, Nano Lett 11 (2011) 2905.

[120] S.J. Guo, S.H. Sun, J Am Chem Soc 134 (2012) 2492.

[121] S.J. Guo, S. Zhang, L.H. Wu, S.H. Sun, Angew Chem Int Edit 51 (2012) 11770.

[122] T. Lin, Y. Tang, Y. Wang, H. Bi, Z. Liu, F. Huang, X. Xie, M. Jiang, Energy Environ. Sci. 6 (2013) 1283.

[123] O.C. Compton, A. Abouimrane, Z. An, M.J. Palmeri, L.C. Brinson, K. Amine, S.T. Nguyen, Small 8 (2012) 1110.

[124] H. Gao, F. Xiao, C.B. Ching, H. Duan, ACS Appl Mater Interfaces 4 (2012) 2801.

[125] L. Cao, F. Xu, Y.Y. Liang, H.L. Li, Adv. Mater. 16 (2004) 1853.

[126] C. Zhang, R. Hao, H. Yin, F. Liu, Y. Hou, Nanoscale 4 (2012) 7326.

[127] M.R. Palacin, Chem Soc Rev 38 (2009) 2565.

[128] J. Liu, J. Jiang, C. Cheng, H. Li, J. Zhang, H. Gong, H.J. Fan, Adv Mater 23 (2011) 2076.

[129] S. Xiong, C. Yuan, X. Zhang, B. Xi, Y. Qian, Chemistry 15 (2009) 5320.

[130] Q. Lu, J.G. Chen, J.Q. Xiao, Angew Chem Int Ed Engl 52 (2013) 1882.

[131] X. Lang, A. Hirata, T. Fujita, M. Chen, Nat. Nanotechnol. 6 (2011) 232.

[132] J. Deng, H. Ji, C. Yan, J. Zhang, W. Si, S. Baunack, S. Oswald, Y. Mei, O.G.

Schmidt, Angew Chem Int Ed Engl 52 (2013) 2326.

[133] B. Wang, X. Li, X. Zhang, B. Luo, Y. Zhang, L. Zhi, Adv Mater (2013)

[134] F. Nacimiento, P. Lavela, J.L. Tirado, J. Miguel Jimenez-Mateos, J. Solid State Electrochem. 16 (2012) 953.

[135] M.-Y. Li, C.-L. Liu, M.-R. Shi, W.-S. Dong, Electrochim. Acta 56 (2011) 3023.

[136] S. Mao, Z. Wen, T. Huang, Y. Hou, J. Chen, Energy Environ. Sci. 7 (2014) 609.

[137] X. Huang, Z. Zeng, Z. Fan, J. Liu, H. Zhang, Adv. Mater. (2012)

[138] Z. Jian, B. Zhao, P. Liu, F. Li, M. Zheng, M. Chen, Y. Shi, H. Zhou, Chem Commun (Camb) 50 (2014) 1215.

[139] X. Huang, X. Qi, F. Boey, H. Zhang, Chem Soc Rev 41 (2012) 666.

[140] X. Huang, X. Qi, F. Boey, H. Zhang, Chem. Soc. Rev. 41 (2012) 666.

[141] C. Xu, B. Xu, Y. Gu, Z. Xiong, J. Sun, X.S. Zhao, Energy Environ. Sci. 6 (2013) 1388.

[142] H.-J. Choi, S.-M. Jung, J.-M. Seo, D.W. Chang, L. Dai, J.-B. Baek, Nano Energy 1 (2012) 534.

[143] M.M. Liu, R.Z. Zhang, W. Chen, Chem Rev 114 (2014) 5117.

[144] R.N. Nasim Khan, N. Mahmood, C. Lv, G. Sima, J. Zhang, J. Hao, Y. Hou, Y. Wei, RSC Advances 4 (2014) 7374.

[145] R. Mukherjee, A.V. Thomas, A. Krishnamurthy, N. Koratkar, ACS Nano 6 (2012) 7867.

[146] Y. Wang, J.J. Wu, Y.F. Tang, X.J. Lii, C.Y. Yang, M.S. Qin, F.Q. Huang, X. Li, X. Zhang, Acs Appl Mater Inter 4 (2012) 4246.

[147] C.Z. Zhang, N. Mahmood, H. Yin, F. Liu, Y.L. Hou, Adv Mater 25 (2013) 4932.

[148] P. Chen, L. Guo, Y. Wang, J. Power Sources 222 (2013) 526.

[149] B. Hertzberg, A. Alexeev, G. Yushin, Journal of the American Chemical Society $132(2010) 8548$.

[150] B. Luo, B. Wang, M. Liang, J. Ning, X. Li, L. Zhi, Adv Mater 24 (2012) 1405. 
[151] Y.J. Hong, M.Y. Son, Y.C. Kang, Adv Mater (2013)

[152] Y.X. Yin, S. Xin, Y.G. Guo, L.J. Wan, Angew Chem Int Edit 52 (2013) 13186.

[153] N. Li, M. Zheng, H. Lu, Z. Hu, C. Shen, X. Chang, G. Ji, J. Cao, Y. Shi, Chem Commun (Camb) 48 (2012) 4106.

[154] J. Kim, D.-J. Lee, H.-G. Jung, Y.-K. Sun, J. Hassoun, B. Scrosati, Adv. Funct. Mater. 23 (2013) 1076.

[155] Y. Yang, G. Yu, J.J. Cha, H. Wu, M. Vosgueritchian, Y. Yao, Z. Bao, Y. Cui, ACS Nano 5 (2011) 9187.

[156] J. Jin, Z. Wen, G. Ma, Y. Lu, Y. Cui, M. Wu, X. Liang, X. Wu, RSC Advances 3 (2013) 2558.

[157] B. Ding, C. Yuan, L. Shen, G. Xu, P. Nie, Q. Lai, X. Zhang, Journal of Materials Chemistry A 1 (2013) 1096.

[158] H. Wang, Y. Yang, Y. Liang, J.T. Robinson, Y. Li, A. Jackson, Y. Cui, H. Dai, Nano Lett 11 (2011) 2644.

[159] Z.Q. Peng, S.A. Freunberger, Y.H. Chen, P.G. Bruce, Science 337 (2012) 563.

[160] R. Black, B. Adams, L.F. Nazar, Adv. Energy Mater. 2 (2012) 801.

[161] R. Cao, J.S. Lee, M.L. Liu, J. Cho, Adv. Energy Mater. 2 (2012) 816.

[162] K.M. Abraham, Z. Jiang, J Electrochem Soc 143 (1996) 1.

[163] Q. Li, X. P., W. Gao, S.G. Ma, G.Q. Zhang, R.G. Cao, J. Cho, H.L. Wang, G. Wu, Adv Mater 26 (2014) 1378.

[164] G. Girishkumar, B. McCloskey, A.C. Luntz, S. Swanson, W. Wilcke, J Phys Chem Lett 1 (2010) 2193.

[165] J. Van Mierlo, G. Maggetto, Fuel Cells 7 (2007) 165.

[166] A. Debart, A.J. Paterson, J. Bao, P.G. Bruce, Angew Chem Int Edit 47 (2008) 4521.

[167] Y.C. Lu, Z.C. Xu, H.A. Gasteiger, S. Chen, K. Hamad-Schifferli, Y. Shao-Horn, J Am Chem Soc 132 (2010) 12170.

[168] Q. Li, R.G. Cao, J. Cho, G. Wu, Phys. Chem. Chem. Phys. (2014) DOI: 10.1039/C4CP00225C.

[169] Y.L. Li, J.J. Wang, X.F. Li, D.S. Geng, M.N. Banis, R.Y. Li, X.L. Sun, Electrochemistry Communications 18 (2012) 12.

[170] H.L. Wang, Y. Yang, Y.Y. Liang, G.Y. Zheng, Y.G. Li, Y. Cui, H.J. Dai, Energ Environ Sci 5 (2012) 7931.

[171] Q. Li, P. Xu, B. Zhang, H. Tsai, J. Wang, H.L. Wang, G. Wu, Chem. Commun. 49 (2013) 10838.

[172] D. Yu, L. Dai, Journal of Physical Chemistry Letters 1 (2010) 467.

[173] X. Yang, J. Zhu, L. Qiu, D. Li, Adv Mater 23 (2011) 2833.

[174] Y. Zhu, S. Murali, M.D. Stoller, K.J. Ganesh, W. Cai, P.J. Ferreira, A. Pirkle, R.M. Wallace, K.A. Cychosz, M. Thommes, D. Su, E.A. Stach, R.S. Ruoff, Science 332 (2011) 1537.

[175] X. Cao, Y. Shi, W. Shi, G. Lu, X. Huang, Q. Yan, Q. Zhang, H. Zhang, Small 7 (2011) 3163.

[176] M.D. Stoller, S.J. Park, Y.W. Zhu, J.H. An, R.S. Ruoff, Nano Lett 8 (2008) 3498.

[177] J. Han, L.L. Zhang, S. Lee, J. Oh, K.-S. Lee, J.R. Potts, J. Ji, X. Zhao, R.S. Ruoff, S. Park, ACS Nano 7 (2013) 19.

[178] W. Yang, Z. Gao, J. Ma, J. Wang, X. Zhang, L. Liu, Dalton Trans 42 (2013) 15706. 
[179] J. Zhu, L. Cao, Y. Wu, Y. Gong, Z. Liu, H.E. Hoster, Y. Zhang, S. Zhang, S. Yang, Q. Yan, P.M. Ajayan, R. Vajtai, Nano Lett (2013)

[180] J. Ji, L.L. Zhang, H. Ji, Y. Li, X. Zhao, X. Bai, X. Fan, F. Zhang, R.S. Ruoff, ACS Nano 7 (2013) 6237.

[181] I. Katsounaros, S. Cherevko, A.R. Zeradjanin, K.J.J. Mayrhofer, Angew Chem Int Edit 53 (2014) 102.

[182] F. Jaouen, E. Proietti, M. Lefevre, R. Chenitz, J.P. Dodelet, G. Wu, H.T. Chung, C.M. Johnston, P. Zelenay, Energ Environ Sci 4 (2011) 114.

[183] C.Z. Zhu, S.J. Dong, Nanoscale 5 (2013) 1753.

[184] Z.W. Chen, D. Higgins, A.P. Yu, L. Zhang, J.J. Zhang, Energ Environ Sci 4 (2011) 3167.

[185] X.J. Zhou, J.L. Qiao, L. Yang, J.J. Zhang, Adv Energy Mater 4 (2014) 201301523. [186] Q. Li, R. Cao, J. Cho, G. Wu, Adv Energy Mater 4 (2014) 201301415.

[187] D.S. Yu, E. Nagelli, F. Du, L.M. Dai, J Phys Chem Lett 1 (2010) 2165.

[188] Y.Y. Liang, Y.G. Li, H.L. Wang, J.G. Zhou, J. Wang, T. Regier, H.J. Dai, Nat. Mater. 10 (2011) 780.

[189] Y.Y. Liang, H.L. Wang, J.G. Zhou, Y.G. Li, J. Wang, T. Regier, H.J. Dai, J. Am. Chem. Soc. 134 (2012) 3517.

[190] H.L. Wang, Y.Y. Liang, Y.G. Li, H.J. Dai, Angew. Chem. Int. Ed. 50 (2011) 10969.

[191] Q. He, Q. Li, S. Khene, X. Ren, F.E. López-Suárez, D. Lozano-Castello, A. Bueno-López, G. Wu, J. Phys. Chem. C 117 (2013) 8697.

[192] R.G. Cao, R. Thapa, H. Kim, X.D. Xu, M. Kim, Q. Li, N. Park, M.L. Liu, J. Cho, Nat. Commun. 4 (2013) 2076.

[193] H.T. Chung, J.H. Won, P. Zelenay, Nat. Commun. 4 (2013) 1922.

[194] M. Lefevre, E. Proietti, F. Jaouen, J.P. Dodelet, Science 324 (2009) 71.

[195] Q. Li, P. Xu, B. Zhang, G. Wu, H.T. Zhao, E.G. Fu, H.L. Wang, Nanoscale 5 (2013) 7397.

[196] S.J. Guo, S. Zhang, S.H. Sun, Angew Chem Int Edit 52 (2013) 8526.

[197] S.J. Guo, D.G. Li, H.Y. Zhu, S. Zhang, N.M. Markovic, V.R. Stamenkovic, S.H. Sun, Angew Chem Int Edit 52 (2013) 3465.

[198] S.J. Guo, S. Zhang, D. Su, S.H. Sun, J Am Chem Soc 135 (2013) 13879.

[199] S.J. Guo, S. Zhang, X.L. Sun, S.H. Sun, J Am Chem Soc 133 (2011) 15354.

[200] H.Y. Zhu, S. Zhang, S.J. Guo, D. Su, S.H. Sun, J Am Chem Soc 135 (2013) 7130.

[201] J. Suntivich, K.J. May, H.A. Gasteiger, J.B. Goodenough, Y. Shao-Horn, Science 334 (2011) 1383.

[202] I.C. Man, H.Y. Su, F. Calle-Vallejo, H.A. Hansen, J.I. Martinez, N.G. Inoglu, J. Kitchin, T.F. Jaramillo, J.K. Norskov, J. Rossmeisl, Chemcatchem 3 (2011) 1159.

[203] H. Dau, C. Limberg, T. Reier, M. Risch, S. Roggan, P. Strasser, Chemcatchem 2 (2010) 724.

[204] C.C.L. McCrory, S.H. Jung, J.C. Peters, T.F. Jaramillo, J Am Chem Soc 135 (2013) 16977.

[205] S. Chen, J.J. Duan, W. Han, S.Z. Qiao, Chem Commun 50 (2014) 207.

[206] S. Chen, J.J. Duan, J.R. Ran, M. Jaroniec, S.Z. Qiao, Energ Environ Sci 6 (2013) 3693.

[207] C.G. Morales-Guio, L.-A. Stern, X. Hu, Chemical Society Reviews (2014) 
[208] W.-F. Chen, J.T. Muckerman, E. Fujita, Chemical Communications 49 (2013) 8896.

[209] T.F. Jaramillo, K.P. Jorgensen, J. Bonde, J.H. Nielsen, S. Horch, I. Chorkendorff, Science 317 (2007) 100.

[210] Y.G. Li, H.L. Wang, L.M. Xie, Y.Y. Liang, G.S. Hong, H.J. Dai, J Am Chem Soc 133 (2011) 7296.

[211] Y. Zheng, Y. Jiao, Y.H. Zhu, L.H. Li, Y. Han, Y. Chen, A.J. Du, M. Jaroniec, S.Z. Qiao, Nat Commun 5 (2014)

[212] J. Zhang, J. Yu, M. Jaroniec, J.R. Gong, Nano Letters 12 (2012) 4584.

[213] U. Sim, T.-Y. Yang, J. Moon, J. An, J. Hwang, J.-H. Seo, J. Lee, K.Y. Kim, J. Lee, S. Han, B.H. Hong, K.T. Nam, Energy \& Environmental Science (2013)

[214] Y. Hou, F. Zuo, A. Dagg, P. Feng, Nano Letters 12 (2012) 6464.

[215] W. Tu, Y. Zhou, Q. Liu, Z. Tian, J. Gao, X. Chen, H. Zhang, J. Liu, Z. Zou, Advanced Functional Materials 22 (2012) 1215.

[216] X. Guo, C. Hao, G. Jin, H.-Y. Zhu, X.-Y. Guo, Angewandte Chemie International Edition 53 (2014) 1973. 


\section{Figure Captions}

Figure 1. Common methods used for graphene production. Reprinted with permission from [34]. Copyrights 2012 Nature Publishing Group.

Figure 2. (a) Graphite concentration measured after centrifugation for a range of solvents plotted versus solvent surface tension. Shown on the right axis is the percentage of material remaining after centrifugation. On the top axis, the surface tension has been transformed into surface energy using a universal value for surface entropy of $0.1 \mathrm{~mJ} / \mathrm{K} \mathrm{m}$. The horizontal arrow shows the approximate range of the reported literature values for the surface energy of graphite. Reprinted with permission from [35]. Copyrights 2008 Nature Publishing Group. (b) Concentration of dispersed graphene in NMP as a function of sonication time. The line illustrates square root behavior. Insets show photos of dispersions after two different sonication times and the structure of the solvent. (c) Length of size-selected flakes plotted as a function of final centrifugation rate. Inset shows flakes found after final centrifugation at $3000 \mathrm{rpm}$ (small flake) and $5000 \mathrm{rpm}$ (large flakes). Scale bar $=500 \mathrm{~nm}$. Reprinted with permission from [37]. Copyrights 2013 American Chemical Society.

Figure 3. Schematic illustration of solvothermal assisted exfoliation and dispersion of graphene sheets in acetonitrile: (a) pristine expandable graphite; (b) expanded graphene; (c) insertion of acetonitile into the interlayers of the expanded graphene; (d) exfoliated graphene sheets stabilized by acetonitrile; (e) photograph of graphene samples obtained in different conditions. Reprinted with permission from [53]. Copyrights 2009 Springer.

Figure 4. (a) DFT model for various doped nitrogen into graphene (blue: nitrogen; grey: carbon; red: oxygen). (b) Charge distribution and (c) spin density distribution on the N-graphene with pyridine structure $\left(\mathrm{C}_{45} \mathrm{NH}_{20}\right)$. The number on the circle is the number of atom. The fractions on the side of these atoms in (b) are atomic charge value (denominator) and spin density (numerator) value on the atoms. In (c) spin density distributes on the electron density isovalue plane. Reprinted with permission from [70]. Copyrights 2011 American Chemical Society.

Figure 5. Synthesis of $\mathrm{N}$-graphene- $\mathrm{Co}_{3} \mathrm{Sn}_{2} / \mathrm{Co}$ and its electrochemical mechanism for reversible $\mathrm{Li}^{+}$storage; conductivity enhancement effect of $\mathrm{N}$-graphene. Reprinted with permission from [15]. Copyrights 2013 American Chemical Society.

Figure 6. (a) Schematic illustration of the preparation of the $\mathrm{N}$-graphene- $\mathrm{Ni}_{3} \mathrm{~S}_{4}$ composite, (b) TEM images of $\mathrm{N}$-graphene- $\mathrm{Ni}_{3} \mathrm{~S}_{4}$ composite (inset plot shows the NPs distribution). Reprinted with permission from [18]. Copyrights 2013 Wiley. (c) SEM image of a typical microfiber with conformal coating of $\mathrm{MnO}_{2}$ nanostructures. (Inset) High magnification SEM image showing the nanoflower structure of electrodeposited $\mathrm{MnO}_{2}$ particles and a clear interface between $\mathrm{MnO}_{2}$ 
nanoflower and underneath graphene nanosheets. Scale bars are 5 and $1 \mu \mathrm{m}$ for main figure and inset. Reprinted with permission from [119]. Copyrights 2011 American Chemical Society.

Figure 7. (a)/(b) TEM images of graphene and graphene-FePt NPs via the solution phase-based self-assembly method. (c) Polarization curves for ORR of different Pt-catalysts in the $\mathrm{O}_{2}$ saturated $0.1 \mathrm{M} \mathrm{HClO}_{4}$ solution (The potential scan rate was $10 \mathrm{mV} / \mathrm{s}$ and the electrode rotation speed was $1600 \mathrm{rpm}$ ); (d) The ORR specific activities of the graphene-FePt NPs, the grapheneFePt NPs annealed $100^{\circ} \mathrm{C}$ and the commercial C-Pt catalyst. Reprinted with permission from [120]. Copyrights 2012 American Chemical Society.

Figure 8. (a) Cyclic behavior of $\mathrm{Co}_{3} \mathrm{~S}_{4}$ and the graphene- $\mathrm{Co}_{3} \mathrm{~S}_{4}$ with a columbic efficiency at a rate of $0.2 \mathrm{C}$ between $0-3 \mathrm{~V}$ vs. $\mathrm{Li}^{+} / \mathrm{Li}$. Reprinted with permission from [19]. Copyrights 2013 Wiley. (b) Cycle performance of P-Graphene and graphene at a current rate of $0.1 \mathrm{~A} / \mathrm{g}$ in the voltage range of 3-0.01 V vs. $\mathrm{Li}^{+} / \mathrm{Li}$. Reprinted with permission from [147]. Copyrights 2013 Wiley. (c) TEM image of the rGO-Ge/C. Reprinted with permission from [102]. Copyrights 2012 American Chemical Society. (d) TEM images of rGO-Sn/C nanocables. The lower part is an enlarged image of the area marked by the box in the upper part. Reprinted with permission from [150]. Copyrights 2012 Wiley. (e) High-magnification TEM image of N-graphene$\mathrm{Co}_{3} \mathrm{Sn}_{2} / \mathrm{Co}$ hybrid (Red circle in the inset shows the thickness of Co shell). (f) Comparison of discharge capacities of $\mathrm{Co}_{2} \mathrm{SnO}_{4}, \mathrm{~N}$-graphene, N-graphene- $\mathrm{Co}_{2} \mathrm{SnO}_{4}, \mathrm{Co}_{3} \mathrm{Sn}_{2} / \mathrm{Co}$, N-grapheneannealed and $\mathrm{N}$-graphene- $\mathrm{Co}_{3} \mathrm{Sn}_{2} / \mathrm{Co}$ hybrid tested at a current density of $250 \mathrm{~mA} / \mathrm{g}$ in the range of 0.005-3 V vs. $\mathrm{Li}^{+} / \mathrm{Li}$. Reprinted with permission from [15]. Copyrights 2013 American Chemical Society.

Figure 9. (a) Schematic presentation of architecture design. (b) TEM image of graphene-PEGsulfur composite. (c) Cyclic performance of the composite. Reprinted with permission from [158]. Copyrights 2011American Chemical Society.

Figure 10. (a, b) TEM and HR-TEM images of the as-prepared rGO- $\mathrm{Mn}_{3} \mathrm{O}_{4}$ nanocomposites with an rGO to $\mathrm{Mn}_{3} \mathrm{O}_{4}$ mass ratio of 4:1. (c) ORR steady-state RDE polarization curves for various catalysts in $\mathrm{O}_{2}$-saturated $0.1 \mathrm{M} \mathrm{LiPF}_{6}$ in the DME electrolyte. Rotating speed: $900 \mathrm{rpm}$; room temperature; (d) initial discharge performance of various catalysts at a current density of 50 $\mathrm{mA} / \mathrm{g}$ in $\mathrm{Li}_{-} \mathrm{O}_{2}$ battery tests. Reprinted with permission from [169]. Copyrights 2013 Royal Society of Chemistry.

Figure 11. (a) Schematic solvothermal synthesis with GO sheets to afford the $\mathrm{rGO}^{-\mathrm{MoS}_{2}}$ composite. (b) SEM and (inset) TEM images of the rGO-MoS $\mathrm{S}_{2}$ composite. (c) HER polarization curves obtained with $\mathrm{rGO}-\mathrm{MoS}_{2}$, Pt and other controls at a catalyst loading of $0.28 \mathrm{mg} / \mathrm{cm}^{2}$. Reprinted with permission from [210]. Copyrights 2011 American Chemical Society. 


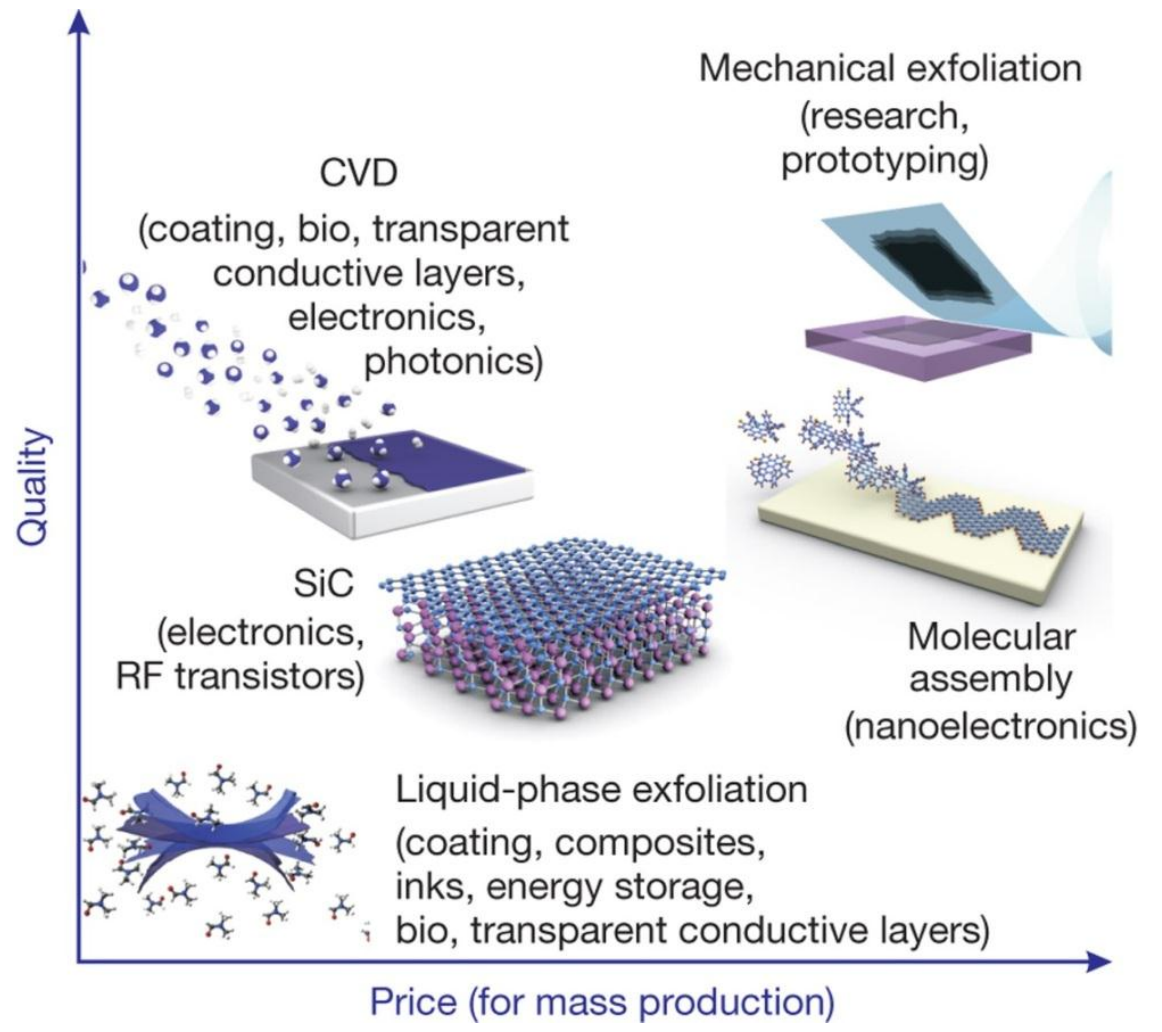

Figure 1 

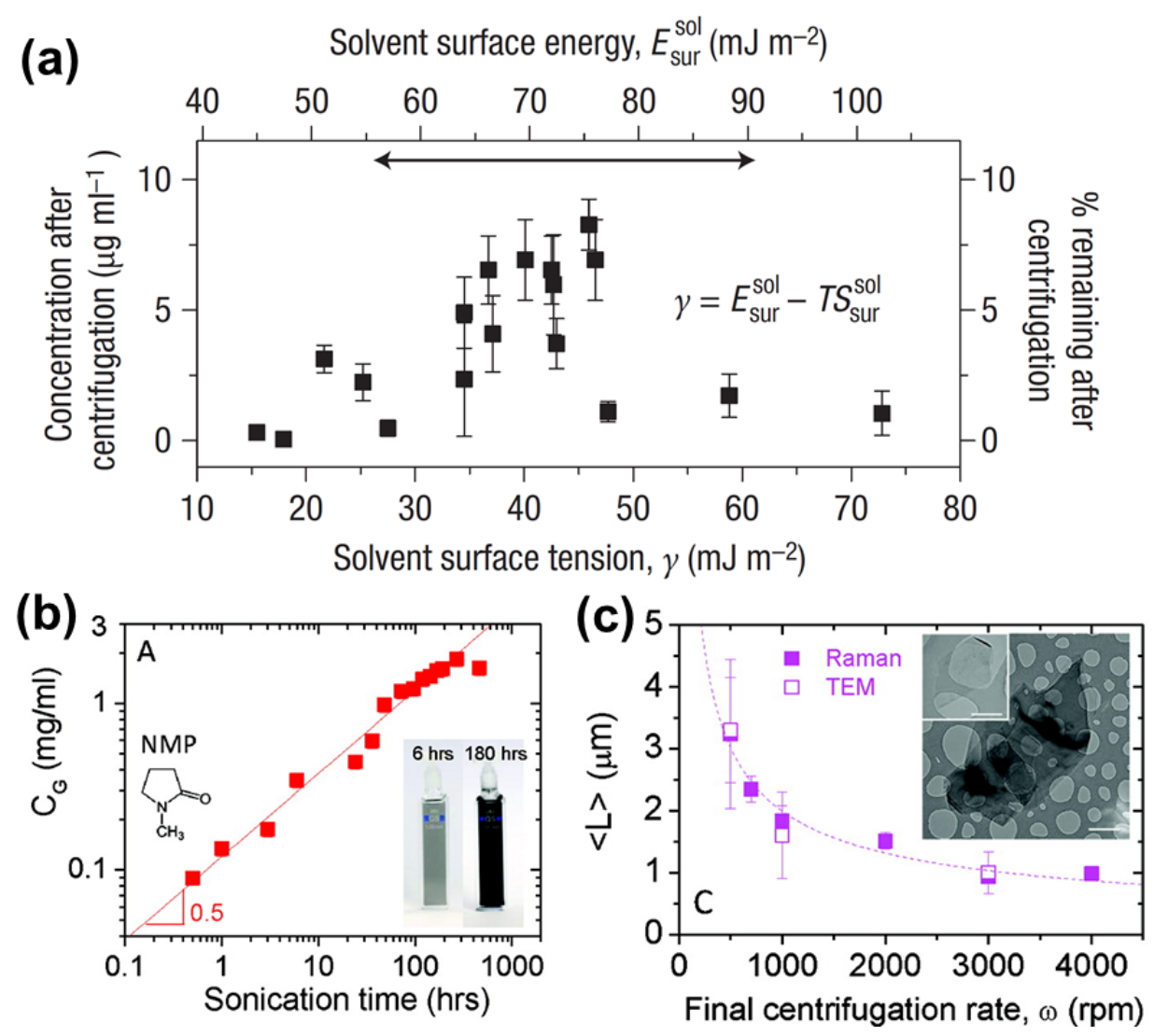

Figure 2 

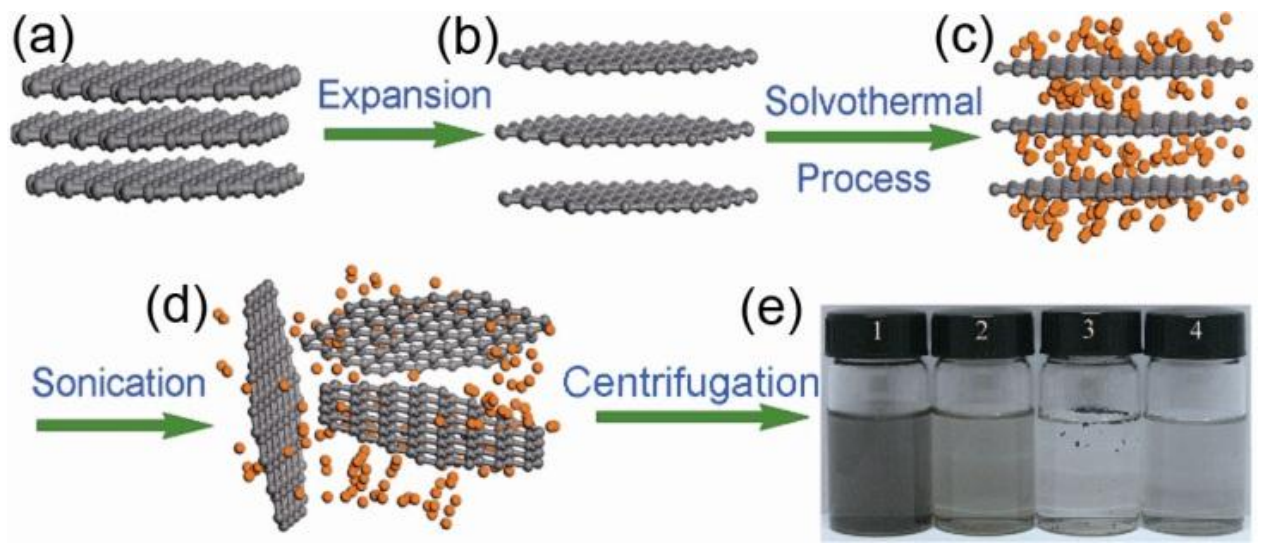

Figure 3 


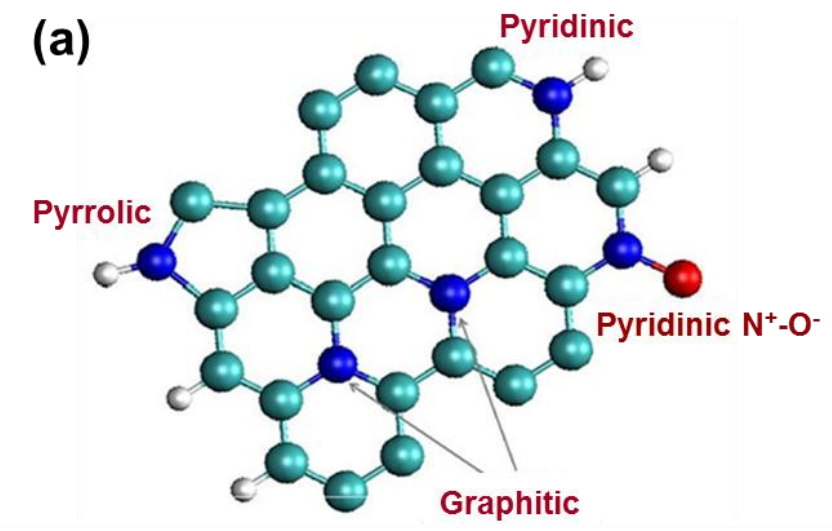

(b)
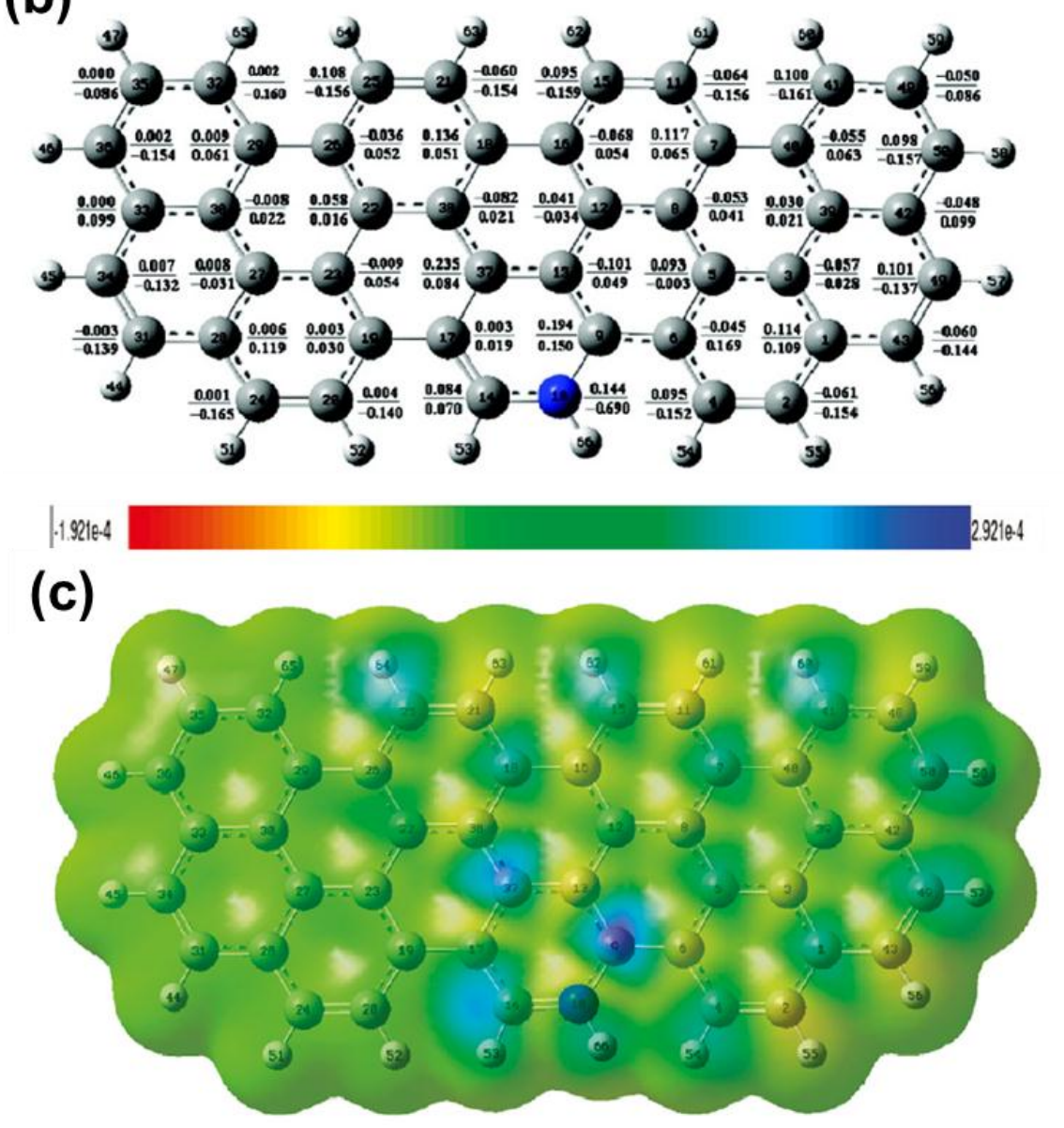

Figure 4 


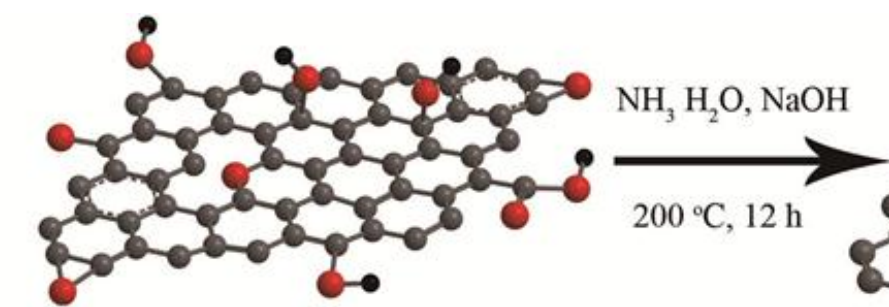

Graphene oxide
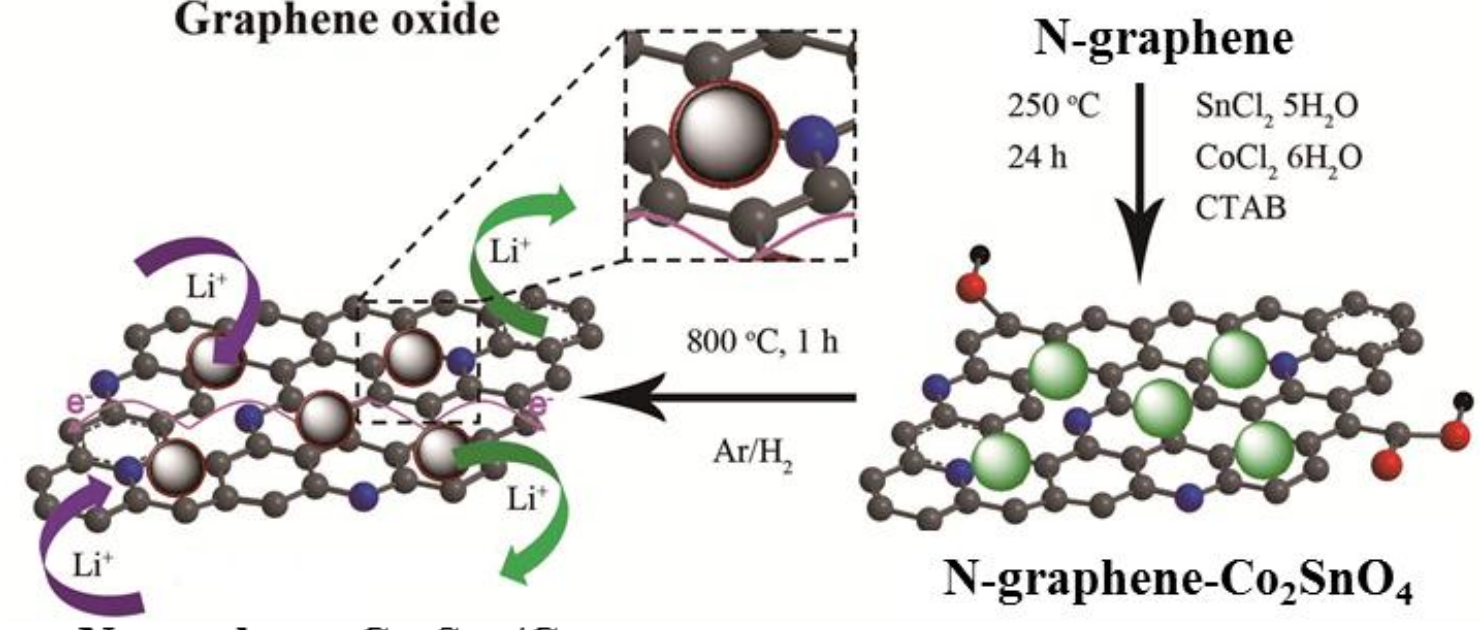

$\mathrm{N}$-graphene-Co $\mathrm{Co}_{3} \mathrm{Sn}_{2} / \mathrm{Co}$

Figure 5 
(a)

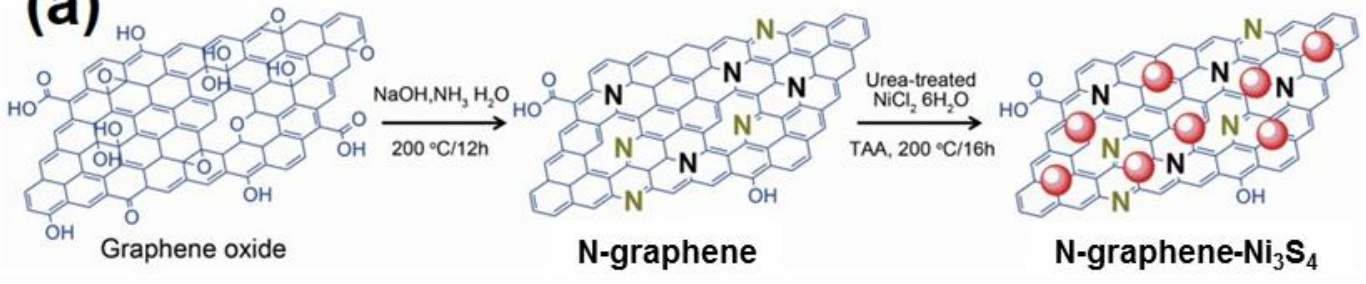

(b)

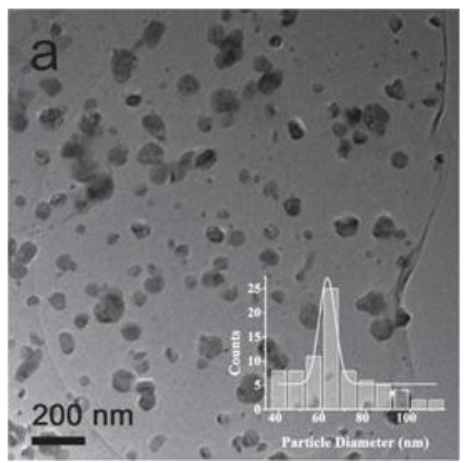

(c)

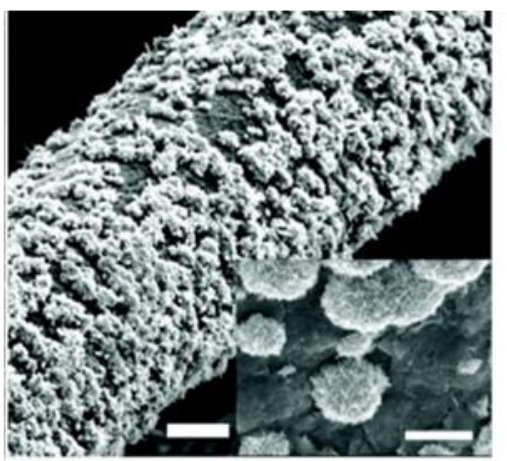

Figure 6 
(a)

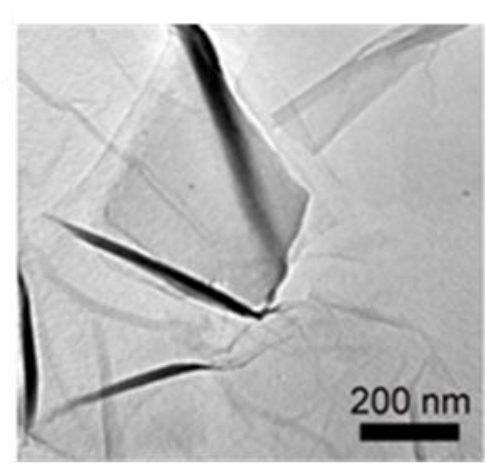

(c)

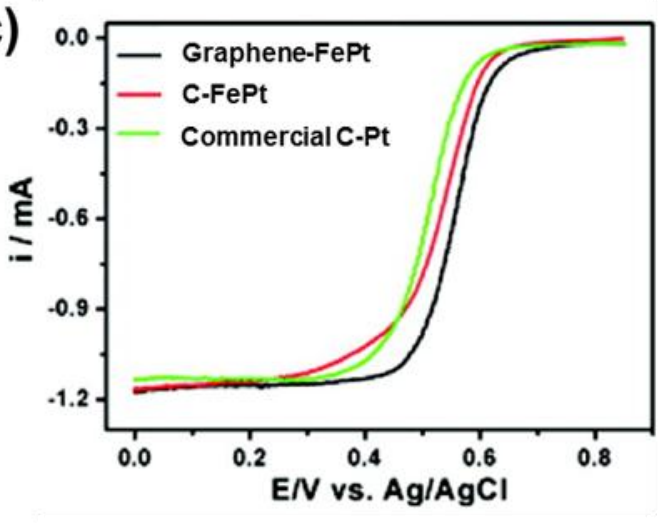

(b)
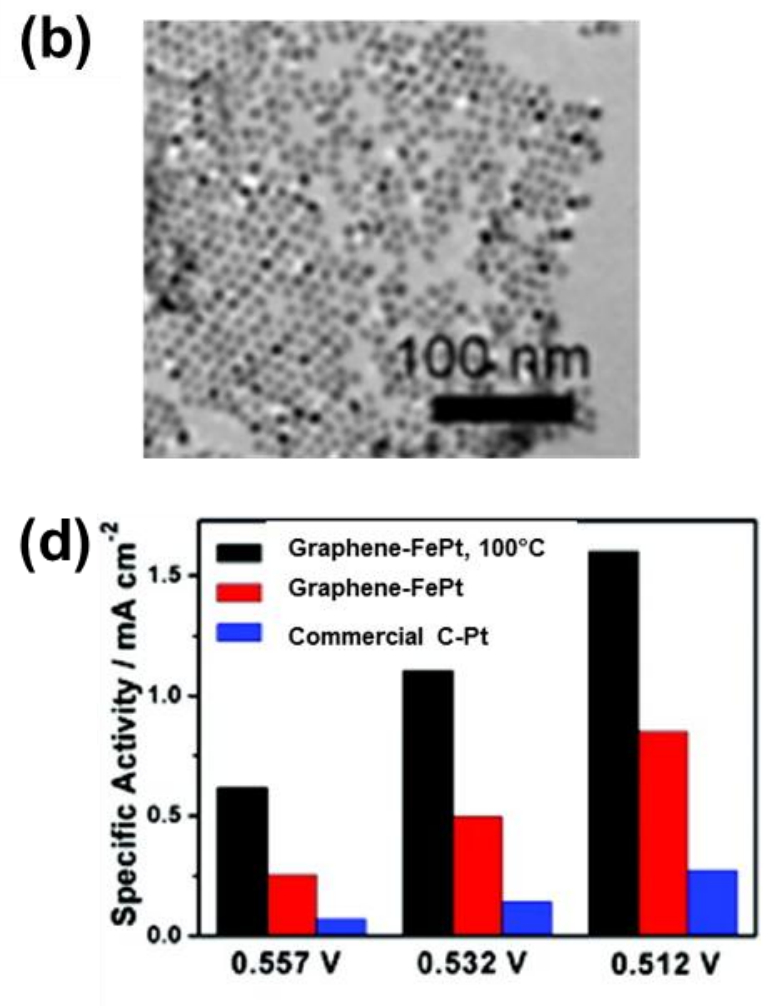

Figure 7 

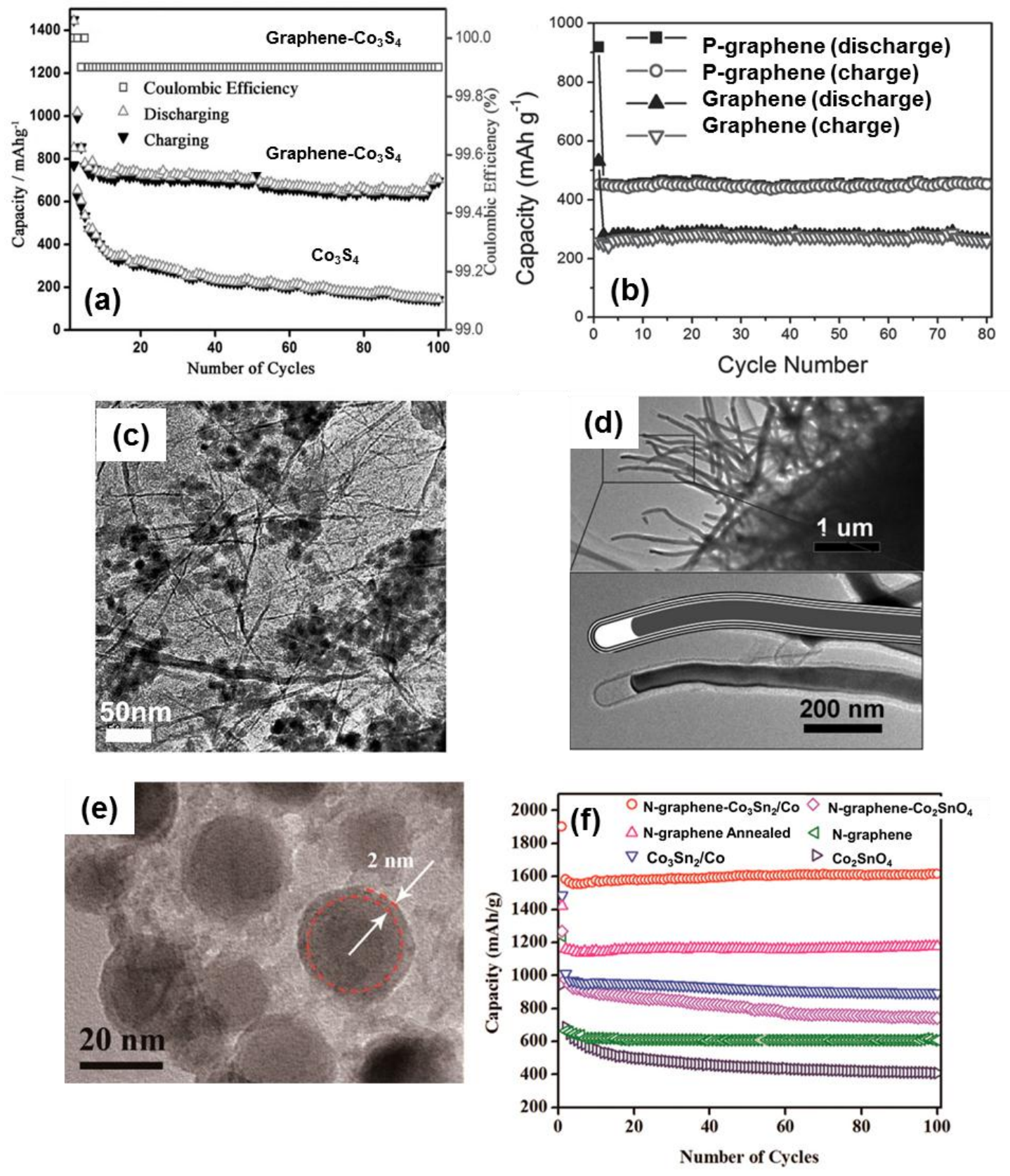

Figure 8 

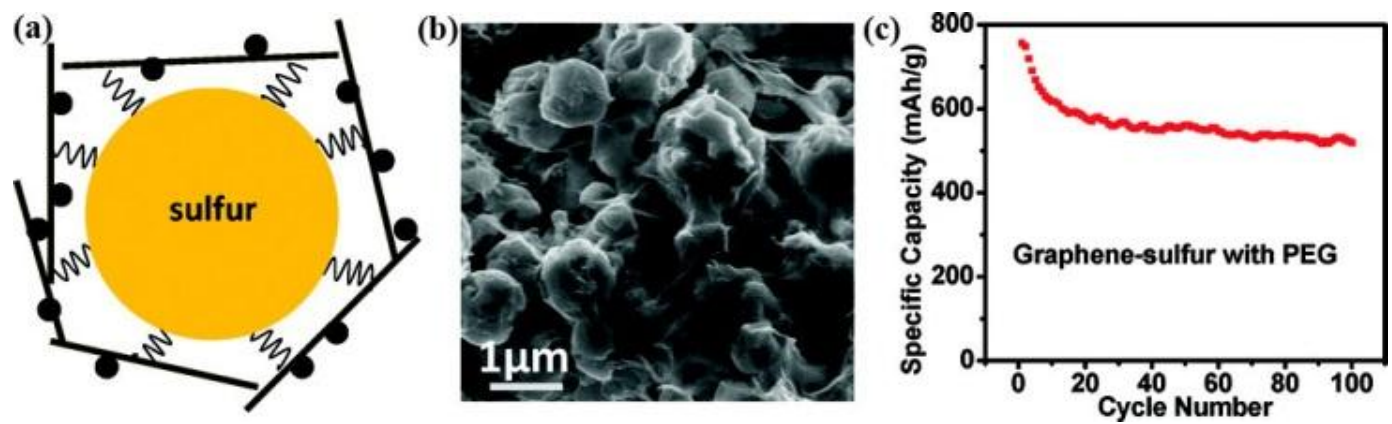

Figure 9 

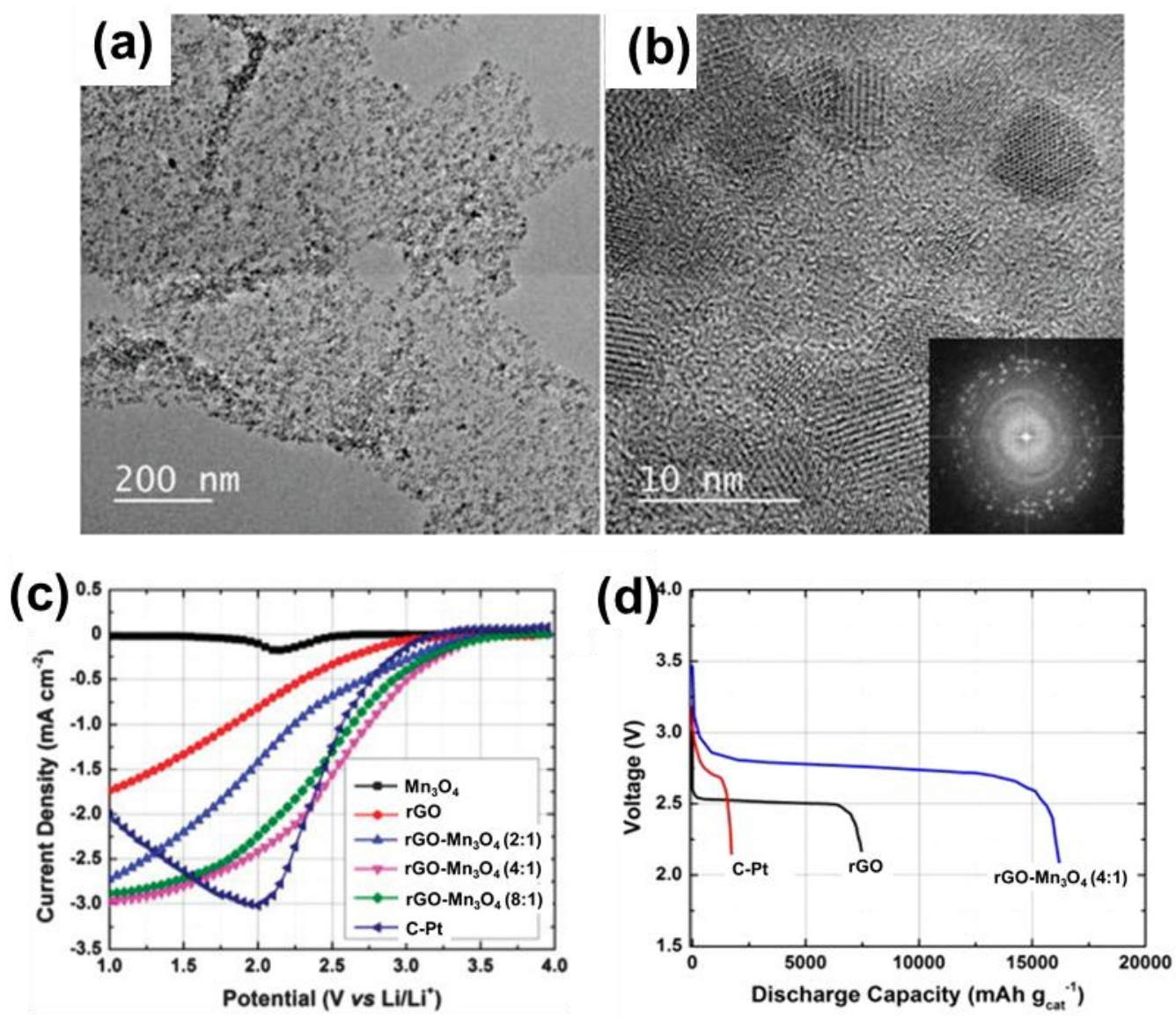

Figure 10 

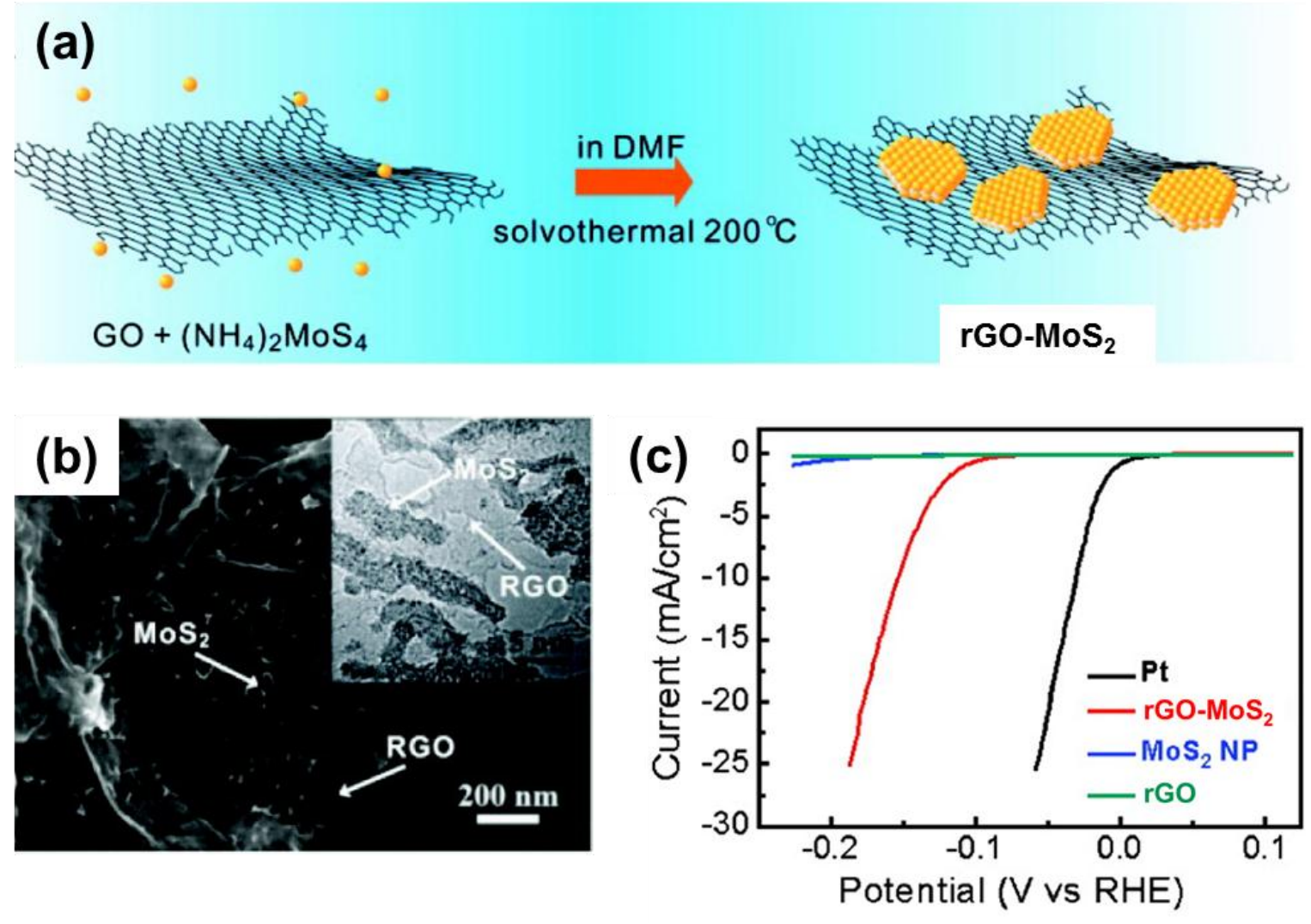

Figure 11 
Table of Content (TOC)

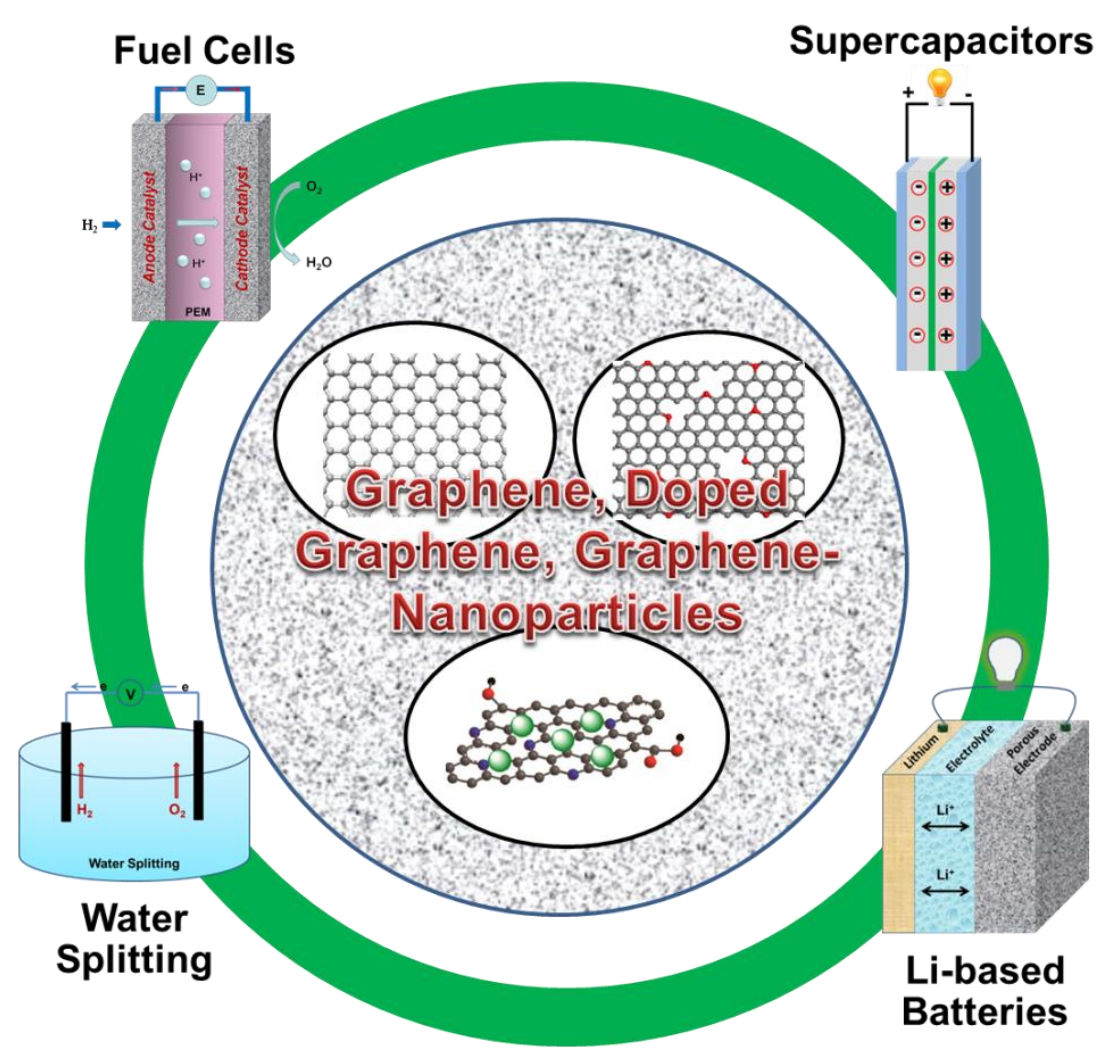

